IZA DP No. 4504

Money for Nothing?

Universal Child Care and Maternal Employment

Tarjei Havnes

Magne Mogstad

October 2009 


\title{
Money for Nothing? Universal Child Care and Maternal Employment
}

\author{
Tarjei Havnes \\ University of Oslo
}

\author{
Magne Mogstad \\ Statistics Norway \\ and IZA
}

\section{Discussion Paper No. 4504 \\ October 2009}

\author{
IZA \\ P.O. Box 7240 \\ 53072 Bonn \\ Germany \\ Phone: +49-228-3894-0 \\ Fax: +49-228-3894-180 \\ E-mail: iza@iza.org
}

\begin{abstract}
Any opinions expressed here are those of the author(s) and not those of IZA. Research published in this series may include views on policy, but the institute itself takes no institutional policy positions.

The Institute for the Study of Labor (IZA) in Bonn is a local and virtual international research center and a place of communication between science, politics and business. IZA is an independent nonprofit organization supported by Deutsche Post Foundation. The center is associated with the University of Bonn and offers a stimulating research environment through its international network, workshops and conferences, data service, project support, research visits and doctoral program. IZA engages in (i) original and internationally competitive research in all fields of labor economics, (ii) development of policy concepts, and (iii) dissemination of research results and concepts to the interested public.
\end{abstract}

IZA Discussion Papers often represent preliminary work and are circulated to encourage discussion. Citation of such a paper should account for its provisional character. A revised version may be available directly from the author. 
IZA Discussion Paper No. 4504

October 2009

\section{ABSTRACT \\ Money for Nothing? Universal Child Care and Maternal Employment}

The strong correlation between child care and maternal employment rates has led previous research to conclude that affordable and readily available child care is a driving force both of cross-country differences in maternal employment and of its rapid growth over the last decades. We analyze the introduction of subsidized, universally accessible child care in Norway. Our precise and robust difference-in-differences estimates reveal that there is little, if any, causal effect of child care on maternal employment, despite a strong correlation. Instead of increasing mothers' labor supply, the new subsidized child care mostly crowds out informal child care arrangements, suggesting a significant net cost of the child care subsidies.

JEL Classification: J13, H40, J21

Keywords: universal child care, female labor force participation

Corresponding author:

Magne Mogstad

Research Dept. of Statistics Norway

$\mathrm{Pb} 8131$ Dep

0033 Oslo

Norway

E-mail: magne.mogstad@ssb.no 


\section{Introduction}

There is a heated debate in the US, Canada and many European countries about a move towards subsidized, universally accessible child care and pre-school, as offered in the Scandinavian countries. For example, the European Union's Presidency formulated in 2002 as a policy goal "to provide childcare by 2010 to at least $90 \%$ of children between 3 years old and the mandatory school age and at least $33 \%$ of children under 3 years of age" (EU, 2002, p. 13). Further, Quebec recently introduced highly subsidized child care, and other Canadian provinces are considering similar policies. In the US, the so-called 'Zero to Five Plan' of US President Obama aims at making states move towards voluntary universal preschool.

Advocates of such policies have argued that good access to affordable child care is critical to facilitate female labor force participation and lower welfare dependency. Indeed, generous child care policies are regularly proposed as a key determinant both of cross country differences in maternal employment (see e.g. Jaumotte, 2003; Del Boca, 2002; Aaberge et al., 2005), and of its dramatic growth over the last decades (see e.g. Attanasio et al., 2008). However, it is possible that publicly provided and/or subsidized child care mostly crowds out other forms of care, yielding little or no increase in total child care use or labor supply. If so, public funding of child care may require a considerable increase in taxes, at a cost to economic efficiency. For example, Rosen (1996) argues that the efficiency distortion of generous Swedish child care policies may be as large as half of total expenditure on child care. It should, therefore, be of significant importance to provide empirical evidence on how universal child care systems have affected maternal employment in countries where they have already been implemented.

In this paper, we analyze the introduction of subsidized, universally accessible child care in Norway in the late 1970s, addressing the impact on the labor force participation of married mothers. ${ }^{1}$ Interestingly, the rates of maternal employment and child care coverage were then quite similar to the situation today in many other developed countries. As Norway has since practiced one of the most expansive child care policies, and achieved one of the highest maternal employment rates, it is therefore not surprising that researchers and policymakers alike have their eyes on the Norwegian child care system and its apparent success. ${ }^{2}$ Our findings suggest, however, that the introduction of universal child care had little, if any, impact on maternal employment. Instead of increasing mothers' labor supply, the new subsidized child care mostly crowds out informal care arrangements, implying a significant net cost of the child care subsidies.

To elicit a causal relationship between child care and maternal employment, we use a difference-indifferences (DD) approach, exploiting a child care reform from late 1975. The reform assigned responsibility for child care to local governments and increased federal subsidies, which generated large variation in child care coverage for children 3-6 years old, both across time and between municipalities. ${ }^{3}$ As described in detail below, formal child care in both the pre-reform period and during the expansion was severely rationed, with informal care arrangements (e.g. relatives, friends, neighbors, and unlicensed care givers) servicing the excess demand. The reform constituted a shock to the supply of formal child care. The supply shocks were, in general, strongest in municipalities where child care was most rationed before the reform. This is likely to be partly because of higher federal subsidy rates for municipalities with low child care coverage prior to the reform, but also due to stronger local political pressure for expansion of formal care in areas where child care was severely rationed.

Our empirical strategy compares the growth in maternal employment rates in municipalities where child care expanded a lot (i.e. the treatment group) and municipalities with little or no increase in child care coverage (i.e. the comparison group). The effect of the child care expansion following the reform is given by the difference in the employment rate of mothers with 3 to 6 year olds before and after the reform, in

\footnotetext{
${ }^{1}$ As in Baker et al. (2008), universal child care is taken to mean child care arrangements that are open for everyone; not that all children were in fact using child care.

${ }^{2}$ In the early 70s, Norwegian mothers were about as likely to work as their sisters in other developed countries, like the US, the UK, and Germany, but pulled ahead during the late 70s and 80s. Today, Norwegian mothers are at the top of international rankings with an about ten percentage points higher employment rate than in these other countries. See for example Dolado et al. (2001)

${ }^{3}$ Throughout this paper, child care coverage rates refer to formal care, including publicly and privately provided child care institutions as well as licensed care givers, all eligible for subsidies from the government.
} 
treatment municipalities relative to comparison municipalities. Our baseline result suggests that the child care expansion caused an average of about 0.06 percentage points increase in maternal employment per percentage point increase in the child care coverage rate. Interpreted in this way, our estimate suggests that the new subsidized formal child care was associated with a 94 percent crowding out of informal care.

Our finding of hardly any causal effect of the large child care expansion on maternal employment may seem at odds with standard labor supply models, where mothers are assumed to replace hours of market work with hours of child care almost one-for-one (see e.g. Heckman, 1974). In these models, the price of child care is effectively a tax on the mother's wage, and any policies driving down this price is expected to have a strong and direct impact on mothers' labor supply decision. To interpret our findings, we outline a parsimonious theoretical framework where mothers relying on informal care on the one hand create political pressure for expanding subsidized formal care, but on the other hand weaken the labor supply response to the expansion. With child care subsidies contingent on a maximum price, the formal child care is rationed and the informal market services the demand surplus. In this case, new subsidized formal child care largely crowds out informal care arrangements, with little effect on total care use and maternal labor supply.

Importantly, our empirical strategy pays close attention to the possibility that mothers with better access to affordable child care are inherently different, and could be more inclined to work in any case. High-quality panel data from administrative registers covering the entire resident population and all licensed care givers in Norway, allow us to take a number of steps to address this concern for omitted variable bias. First of all, the DD approach removes fixed differences in maternal employment between the treatment and comparison areas (for example due to differences in rationing of formal care prior to the reform), in addition to common time-specific changes in employment coinciding with the reform (like a secular nationwide trend in maternal employment). Our estimates are also robust to the inclusion and exclusion of a large set of controls capturing important characteristics of the mother and her spouse. In addition, the low level of aggregation in our data, spanning more than 400 municipalities covering about 4 million persons, allows us to account for geographical heterogeneity by including municipality-specific fixed effects as well as controls for changes in the local labor market conditions. ${ }^{4}$ The results are very similar when including these covariates.

To further increase our confidence in the empirical strategy, we run a battery of specification checks. In particular, we address the two identification assumptions underlying DD estimation from policy changes creating state-time variation, as emphasized by Besley and Case (2000). These assumptions are that the time-effects must be identical between the treatment and comparison group, and that the composition of the groups must remain the same, implying a common time trend between the treatment and comparison group in the absence of the reform. The common trend assumption is supported by the fact that we find no effect of a placebo reform, pretending that the child care expansion took place in the pre-reform period. Nevertheless, our estimates could be biased if treatment municipalities initiated other policies (that we are unaware of) or experienced different economic fluctuations (that are not fully accounted for by the local employment rates) at the same time as the child care reform. To pick up such time-varying effects specific to the treatment area, we add mothers with the youngest child just above the child care age (7 to 10 years old) as a second comparison group. It is heartening to find that this triple-difference approach barely moves the estimated child care effects. Further, we take advantage of having access to panel data, restricting the sample to the same mothers before and after the reform. This removes biases due to unobserved compositional changes over time within the treatment group. By including individual-specific fixed effects, we also eliminate biases owing to permanent unobserved differences between mothers residing in treatment and comparison areas. These specification checks also confirm the picture of almost no effect of child care on maternal employment. We also take several steps to make sure that selective migration of mothers into treatment and comparison areas is not driving our results. Finally, it should be noted that identification from a common trend assumption depends only on what would have happened in the absence of the reform: If, for instance, child care expanded most in municipalities where it was most effective in promoting maternal employment, then this would not pose a threat to identification of the treatment effect on the treated.

\footnotetext{
${ }^{4}$ Heckman et al. (1998) demonstrate the importance in policy evaluations of controlling for variation in the local labor market conditions of those treated by the policy change and the comparison group.
} 
Because of the often slow and uniform expansion of child care over time and space, many previous studies have been confined to rely on limited variation in the data or a long time span to identify the effect of child care on maternal employment. By contrast, our study compares municipalities that differ distinctly in terms of changes in child care coverage within a relatively narrow time frame. The shear strength of the variation in our data implies that any actual effect should be present in our estimates. That we find a very small but precisely estimated effect of the child care expansion, therefore serves as strong evidence of a weak causal link from child care to maternal employment. Importantly, this conclusion holds true also when we estimate the model separately by age, educational attainment, and number of children of the mother.

The paper proceeds by first discussing our study in relation to previous research on child care and maternal labor force participation. Next, Section 3 describes the Norwegian child care system before and after the child care reform, and sketch a parsimonious theoretical framework to interpret the policy changes. Section 4 outlines our empirical strategy, before Section 5 presents the data. Section 6 discusses our main results, and Section 7 reports results from the specification tests. Finally, Section 8 concludes with a discussion of policy implications.

\section{Child care and maternal employment}

There exists a considerable literature on child care and maternal employment. Much attention has been paid to estimating structural parameters of utility functions, used to simulate both labor supply elasticities and the effects of various policy changes. Examples include Blau and Robins (1988), Connelly (1992), Michalopoulos et al. (1992), Kimmel (1998), and Kornstad and Thoresen (2007). In a survey of this strand of the literature, Blau and Currie (2006) report estimated elasticities of employment with respect to price of child care ranging from 0 to values below -1 .

Differences in data sources and sample composition do not appear to account for much of the variation in the estimates. Instead, Blau and Currie (2006) point out two fundamental problems for these studies: Child care access and prices are endogenous to the work decision of mothers, and the availability and cost of informal care is unobserved. A large part of the discrepancy between the estimates is therefore likely to be explained by differences in biases owing to ignoring the substitution between formal and informal child care, misspecifications of functional forms for the employment and child care equations, and, in particular, violations of the exclusion restrictions (e.g. identification through variation in child care access and prices that are not exogenous to the employment decisions).

Some recent studies, to which our paper relates, sidestep these issues by applying quasi-experimental approaches, exploiting policy changes that create time and regional variation in the access to or price of child care. Baker et al. (2008) and Lefebvre and Merrigan (2008) study the implementation of a child care subsidy in Quebec, whereas Lundin et al. (2008) study the introduction of a maximum price in Sweden. Schlosser (2005), Berlinski and Galiani (2007), and Cascio (2009) evaluate the impact of a free public child care/pre school program in Israel, Argentina, and the United States, respectively. All these studies apply a DD approach, but their findings differ substantially. ${ }^{5}$

The results in our paper are consistent with those of Lundin et al. (2008) and Cascio (2009), in finding hardly any effect on the labor supply among married mothers of increased access to (or lower prices on) child care. In comparison, Schlosser (2005), Berlinski and Galiani (2007), Baker et al. (2008), and Lefebvre and Merrigan (2008) report significant positive effects, albeit at the lower range of estimates reported by Blau and Currie (2006). For instance, Baker et al. (2008) find that the introduction of generous child care subsidies in Quebec led to a 14 percentage point increase in child care use, which was associated with a 7.7 percentage point increase in employment; the difference between the rise in employment and the rise in child

\footnotetext{
${ }^{5}$ In a similar vein, Gelbach (2002) uses quarter of birth as an instrument for public kindergarten enrollment of five year olds in the US. He finds that mothers with children in public kindergarten are more likely to be working. However, recent evidence suggests that quarter of birth may not be a valid instrument, see Cascio (2006) for a discussion. Similarly, Simonsen (2009) exploits variation in child care prices across Danish municipalities to estimate the price sensitivity of maternal employment following maternity leave. She finds that the price effect is significantly negative, but smaller than what is found in much of the previous literature.
} 
care utilization reflects a considerable crowding out of informal care arrangements by the new subsidized child care slots.

It is likely that at least part of the discrepancy in the estimates can be explained by differences in the populations studied, the local labor market conditions, and the availability and cost of informal care arrangements. For example, it may be hard to generalize the results from Lundin et al. (2008) to other countries, as the maternal employment rate was as high as 70 percent and child care utilization more than 80 percent before the reform. In comparison, the Norwegian experience from the late 1970s can be of more interest from an international perspective, since many developed countries today have comparable child care coverage and female labor force participation. ${ }^{6}$

Another reason for the differences in the estimates is that the empirical strategies differ in a number of ways. As pointed out by Cascio (2009), one potential problem with some of the studies reporting significant labor supply effects is that the pre-reform trends of the treatment and comparison areas differ significantly. For example, as is evident from Lefebvre and Merrigan (2008), the trend in maternal employment is significantly different in Quebec compared to the rest of Canada prior to the reform. We may, therefore, suspect that the estimated positive effect of this child care reform reflects differential time trends, rather than a true policy impact.

A further concern with the empirical strategies in previous studies is that shocks specific to the treatment areas that coincide with the policy changes may bias the estimates. For instance, the treatment area could have initiated other policies or experienced different economic fluctuation at the same time as the child care reform. As pointed out by Baker et al. (2008), there were several other changes in family and child benefits in Quebec and the rest of Canada around the time of the child care reform, which may confound their estimates.

Previous studies of child care and maternal employment may also suffer from applying their DD approach to repeated cross-sectional data. This may bias the results if there are unobserved compositional changes over time within the treatment group, or permanent unobserved differences between mothers residing in treatment and comparison areas. For example, Cascio (2009) identifies the child care effects from statetime variation based on decennial census data over a 40-year span, which makes unobserved compositional changes likely, especially since she lacks controls for important characteristics, like educational attainment, of the mother and her spouse.

As discussed below, our exceptionally rich data and the battery of specification checks we perform make it possible to arrive at estimates that are potentially less biased than those previously presented using DD approaches.

\section{Background}

In this section, we describe the Norwegian child care system before and after the 1975 reform, and sketch a parsimonious theoretical framework to interpret the policy changes. ${ }^{7}$

The Norwegian Child Care System. In the post-WWII years, the gradual entry on the labor market of particularly married women with children, caused growing demand for out-of-home child care. Alongside the rapid increase in maternal employment, child care coverage has grown dramatically. Figure 1 shows child care coverage rate (for 3 to 6 year olds) as well as labor force participation by gender, marital status and age of the youngest child, in Norway from 1972 to 1996. In 1968, when child care coverage was less than five percent, about 35 percent of mothers with 3 to 6 year olds stated demand for daily child care (NOU, 1972). In the same survey, 34 percent of the latter group of respondents stated that they were in fact using out-of-home child care on a regular basis. Out of these, just 14 percent were in formal child care, consisting of publicly and privately provided child care institutions as well as licensed care givers, while almost 85 percent were using informal arrangements. ${ }^{8}$

\footnotetext{
${ }^{6}$ For example, Norwegian female labor force participation in 1976 was about 50 percent, compared to 2000-levels of around
} 


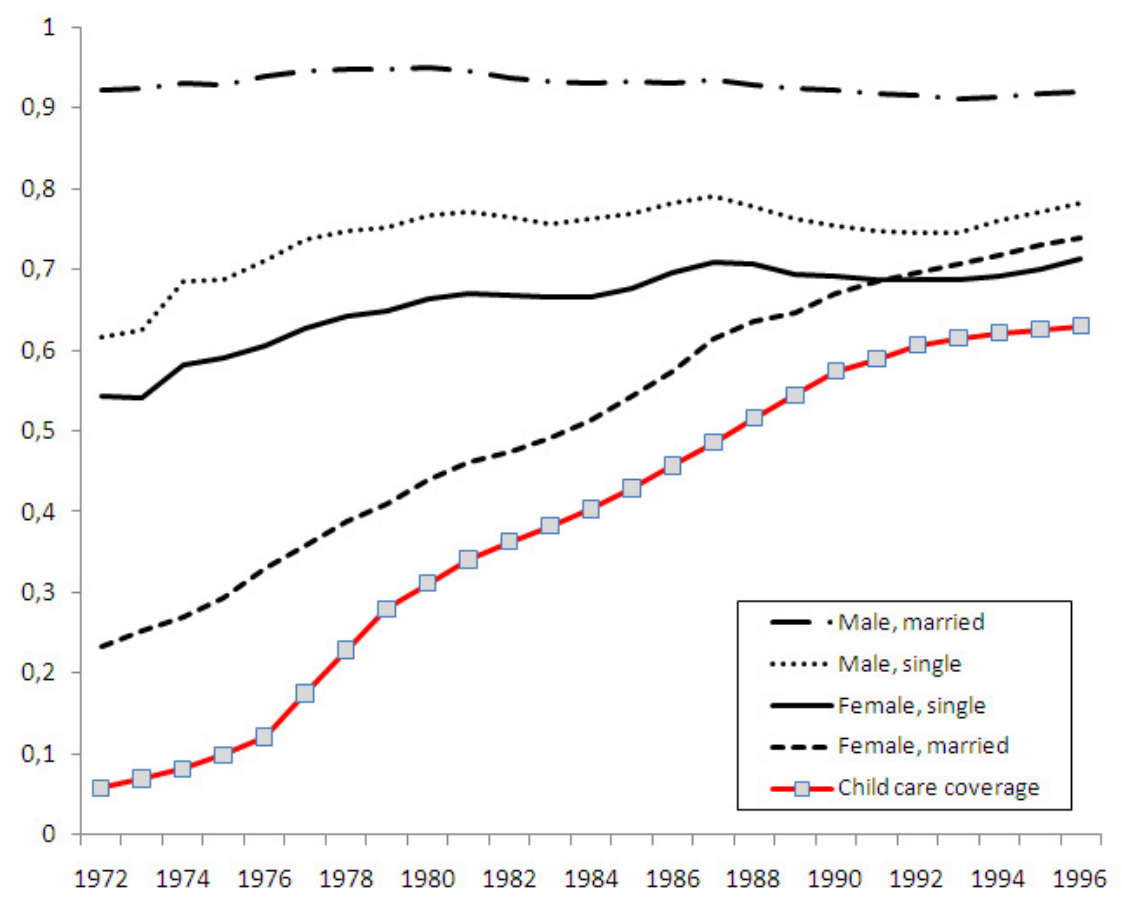

(a) Child care coverage and employment rates by gender and marital status.

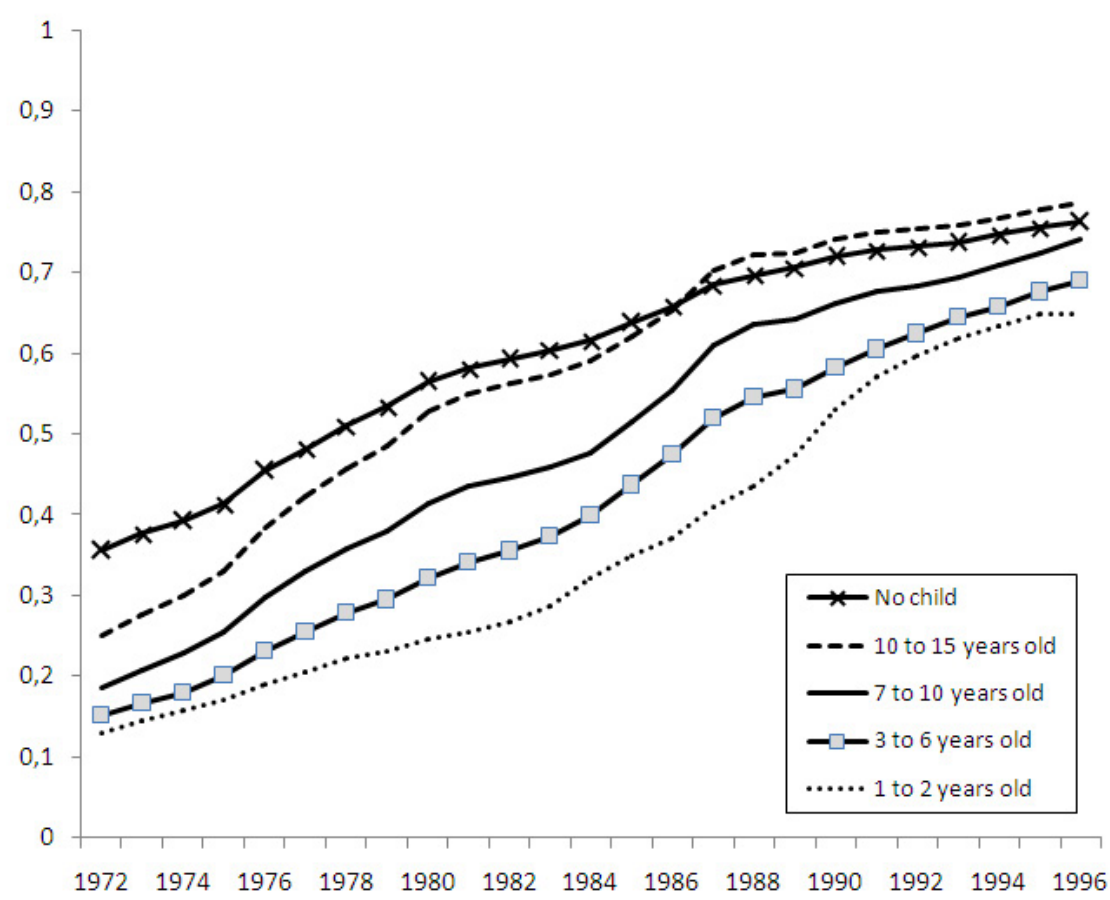

(b) Maternal employment rates by age of youngest child.

Figure 1: Child care coverage and employment rates by gender and marital status, and maternal employment rates by age of youngest child, Norway: 1972-1996

Note: Section 5 describes the data and defines employment. 
The severe rationing of formal child care acted as a background for political progress towards public funding of formal care. In the early 1950s, grants and subsidized loans were temporarily made available for construction and refurbishment of child care institutions, and their operation was regulated by law in 1954 . Federal subsidies to formal child care were assigned a permanent post on the national budget in 1962, and increased over the subsequent ten years from a modest USD 50 per child care place to more than USD 1,200 annually. ${ }^{9}$ The child care subsidies were contingent on a maximum price to be paid by the parents, which in 1972 was about USD 215 per month for full time care (NOU, 1972).

In 1972, the Norwegian government presented the Kindergarten White Paper (NOU, 1972), proposing radical changes in public child care policies. To create positive arenas for child development, and free labor market reserves among mothers, it was argued that formal child care should be made universally available. This marked a strong shift in child care policies, from focusing on children with special needs (in particular disabled children and children from disadvantaged families) to a move towards a universal child care system, offered to the entire population.

In June 1975, The Kindergarten Act was passed by the Norwegian parliament with broad bipartisan political support. It assigned the responsibility for child care to local municipalities, but included federal provisions on educational content, group size, staff skill composition, and physical environment. By increasing the level of federal subsidies for both running costs in general and investment costs for newly established institutions, the government aimed at quadrupling the number of child care places to reach a total of 100,000 places by $1981 .^{10}$

In the years following the reform, the child care expansion was progressively rolled out at a strong pace, with federal funding more than doubling from USD 34.9 million in 1975 to 85.8 million in 1976, before reaching 107.3 million in $1977 .{ }^{11}$ This implied an increase in the federal coverage of running costs from about $10 \%$ in 1973 to $17,6 \%$ in 1976, and further to $30 \%$ in 1977 . From 1976, newly established child care places received additional federal funds for a period of five years: Municipalities with a child care coverage rate below $10 \%$ were awarded $60 \%$ more subsidies, whereas other municipalities were awarded $40 \%$ extra.

Altogether, the reform constituted a substantial positive shock to the supply of formal child care. In succeeding years, the previously slow expansion in subsidized child care accelerated rapidly, as shown in Figure 1. From a total coverage rate of less than 10 percent for 3 to 6 year olds in 1975, coverage had shot up above 28 percent by 1979 . Over the period, a total of more than 38,000 child care places were established, more than a doubling in child care places compared to 1975. By contrast, there was almost no child care coverage for 1 and 2 year olds during this period. Table 1 reports child care institutions by owner biannually from 1975 through 1981, and shows the strong growth in municipal and cooperative child care centers. The share of private centers decreased from 28 percent in 1975 to just over 20 percent in 1981, driven almost entirely by a decline in the share of centers run by private organizations.

Theoretical framework. Figure 2 provides an illustration of how we perceive the market for formal and informal child care before the 1975 reform. The child care system was characterized by subsidized supply contingent on a maximum price, causing substantial rationing of formal child care, which is represented in Panel (a) by a kinked supply curve for formal care. The demand for out-of-home care and the supply of formal care are represented by the curves $D$ and $S .1$, respectively. Formal care is provided at marginal cost net of subsidies up to the maximum price, yielding a normal upward-sloping supply curve. Above the

\footnotetext{
40 percent in Mediterranean countries and around 55 percent in Central European countries (Boeri et al., 2005).

${ }^{7}$ See Leira (1992, ch. 4) for a detailed survey of the history of Norwegian child care policies since WWII.

${ }^{8}$ Relatives stand out as the largest group of informal care givers at 35 percent, followed by play parks at 20 percent, maids at 14 percent, other unlicensed care givers at 10 percent, and finally more irregular arrangements (such as neighbors and friends) at 7 percent (NOU, 1972).

${ }^{9}$ Throughout this paper, all figures are in US dollars, and fixed at 2006-level (NOK/USD = 6.5).

${ }^{10}$ In addition, the price-setting was delegated to local municipalities, abolishing the federally determined maximum parental price for child care subsidies. However, Gulbrandsen et al. (1981) report survey data suggesting that the maximum price to be paid by the parents actually changed little in the years following the reform, and formal child care remained rationed well into the $90 \mathrm{~s}$.

${ }^{11}$ Source: National budgets 1975/76 through 1978/79.
} 
maximum price, formal care is provided at marginal cost excluding subsidies, in the figure taken to be above the scale of the $y$-axis, yielding a vertical supply curve after this point.

In Panel (a), formal care supplied is $b^{s 1}$ at the maximum price. At this price, however, there is a substantial demand surplus, which is serviced by informal care arrangements; Leira (1992) reports that informal care in 1973 serviced almost 90 percent of mothers using out-of-home care on a regular basis. Given the large surplus demand for formal care reported in the survey referred to above, we assume that the (quality-adjusted) price of informal care was higher than the comparable price of formal care. This is illustrated in Panel (b), where we integrate the formal and informal market for child care. Formal care is preferred to informal care below the maximum price, such that the informal market (curve $I .1$ ) only services the demand surplus. The use of formal and informal care are then $b^{s 1}$ and $b^{I 1}$, respectively.

Both mothers using informal care but preferring formal care, and mothers unwilling to use informal care but willing to use formal care at the maximum price, are dissatisfied because of the rationing, and form political pressure for expansion of formal care. In Panel (b), the political pressure from the first group of mothers using informal care is indicated by the shaded rectangle $a$, while the pressure from the second group of mothers is indicated by the shaded triangle $b$. As female wages increased, demand for child care grew, and the political pressure for generous child care policies mounted. This manifested itself in the 1975 child care reform, which implied both a substantial direct shock to the supply of formal child care, and that local governments could pursue separate child care policies, creating large variation in child care coverage both over time and between municipalities. Local governments are likely to have been particularly expansive where the political pressure was relatively strong, that is, in municipalities in which the rationing was severe such that areas $a$ and $b$ in Panel (b) were large. These differences in supply shocks to formal child care are expected to be amplified by the higher federal subsidy rates for municipalities with low child care coverage prior to the reform.

As mothers represented by area $a$ are already using out-of-home care, we would not expect an increase in employment rates for this group from an expansion in formal child care. If anything, substitution from informal to subsidized formal care could generate a negative income-effect, reducing labor supply. The positive effect on maternal employment from the child care expansion should, therefore, come from mothers not using informal care but willing to use formal care at the maximum price, represented by the area $b$. While the political pressure determining the size of the child care expansion depends on both areas, the increase in total child care use and labor supply depends only on area $b$. If area $a$ is relatively large compared to area $b$, an expansion in formal child care may have little impact on total use of out-of-home care and maternal labor supply. To illustrate this point, Panel (c) considers a municipality that significantly expanded its supply of formal child care, to the new level $b^{s 2}$. The actual impact of the new subsidized child care on maternal employment is, however, much smaller, since much of the expansion simply crowds out informal care arrangements. The supply of informal care is now only $b^{I 2}$, compared to $b^{I 1}$ earlier.

Table 1: Child care institutions by ownership structure

\begin{tabular}{|c|c|c|c|c|}
\hline & 1975 & 1977 & 1979 & 1981 \\
\hline Private $(\%)$ & 28.4 & 26.7 & 26.3 & 21.9 \\
\hline Municipality (\%) & 48.6 & 45.4 & 46.9 & 51.2 \\
\hline Church $(\%)$ & 7.3 & 8.0 & 8.6 & 8.6 \\
\hline Cooperatives $(\%)$ & 5.6 & 8.2 & 9.7 & 10.0 \\
\hline No. of child care institutions & 880 & 1,469 & 2,294 & 2,754 \\
\hline No. of children in child care (3-6 y.o.) & 25,536 & 43,239 & 63,218 & 73,152 \\
\hline Coverage rate (3-6 y.o., \%) & 10.0 & 17.6 & 28.1 & 34.2 \\
\hline
\end{tabular}

Notes: Private ownership indicates ownership by a private firm, organization or foundation. Cooperatives are parental or residential. Categories not reported are ownership by state, regions and other. 


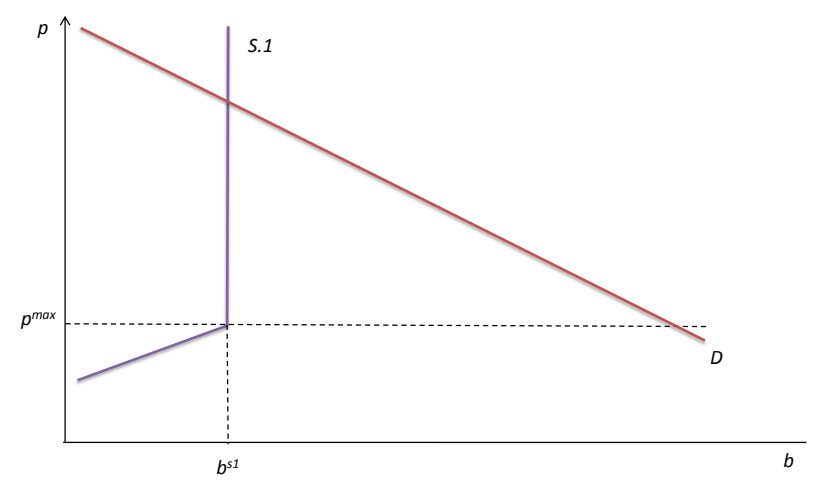

(a) Demand for out-of-home care and supply of formal care

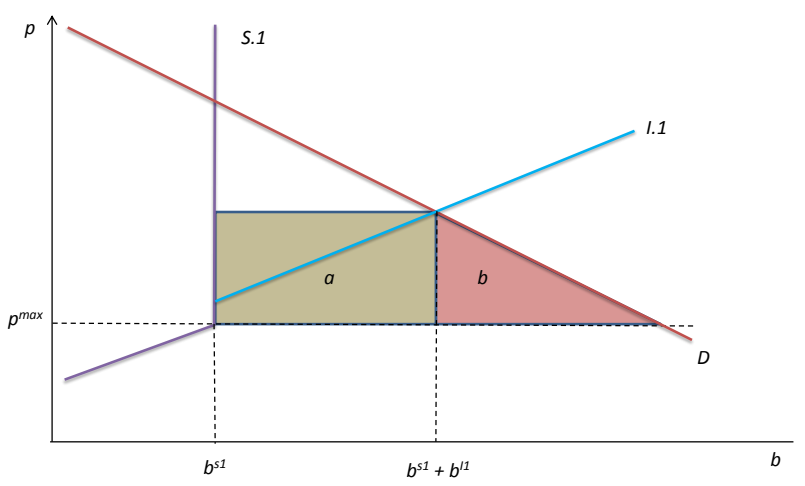

(b) Supply of formal and informal care, and political pressure

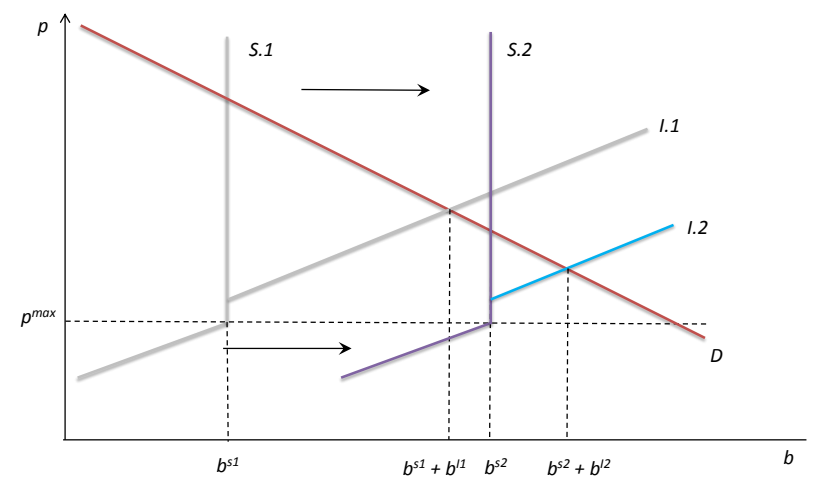

(c) Expansion of formal care crowds out informal care

Figure 2: The market for formal and informal child care

Notes: $D$ denotes the demand for out-of-home care. $S .1$ and $S .2$ denote supply curves for formal care before and after child care expansion. $p^{\max }$ is the maximum price qualifying for subsidies in the formal market. $I .1$ and $I .2$ denotes the quality-adjusted supply curves of informal care. Areas $a$ and $b$ reflect political pressure towards expansion in subsidized formal care from mothers using informal care and mothers unwilling to purchase informal care but willing to use formal care at the maximum price, respectively. 


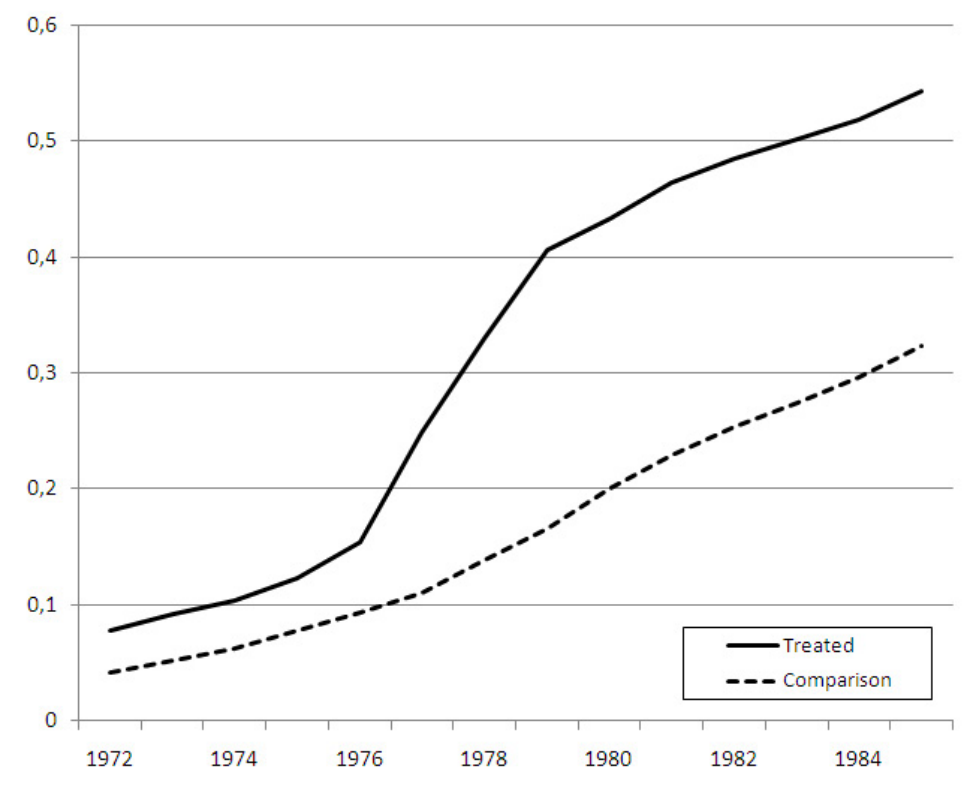

Figure 3: Child care coverage rates for children aged 3-6 by treatment (solid) and comparison group (dashed).

Notes: Treatment (comparison) municipalities are above (below) the median in child care coverage from 1976 to 1979.

\section{Empirical strategy}

To estimate the effect of universal child care on maternal employment we follow recent studies closely in applying a DD approach, exploiting that the supply shocks to formal child care were larger in some areas than others. Below, we will first describe our main empirical strategy, before discussing alternative specifications addressing potential threats to identification.

Main empirical strategy. Our main empirical strategy is the following: We compare the growth rate in employment from 1976 to 1979 of mothers with children aged 3 to 6 years living in municipalities where child care coverage expanded a lot (that is, the treatment group), with the growth rate for mothers (with children of the same age) who live in municipalities with little or no increase in child care (that is, the comparison group).

The motivation for using 1976 as the first year of the comparison is to give the municipalities some time to respond to the policy change (the law was passed in June of 1975). Also, 1976-1979 was the period with the largest growth in the child care coverage. Finally, to ensure comparability of mothers before and after the reform, we do not want the years of comparison to be too far apart. In the robustness analysis, we make sure that our results are robust to changes in the exact choice of time intervals.

To define the treatment and comparison group, we order the municipalities according to the percentage point increase in child care coverage rates from 1976 to 1979. We then separate the sample at the median, letting the upper half constitute the treatment municipalities and the lower half the comparison municipalities. Figure 3 displays child care coverage before and after the 1975 reform in treatment and comparison municipalities (weighted by population size). The graphs move almost in parallel before the reform, while the child care coverage of the treatment municipalities kinks heavily after the reform. This illustrates that our study compares municipalities that differ distinctly in terms of changes in child care coverage within a narrow time frame. In the robustness analysis, we take several steps to make sure that our results are robust to the exact child care coverage cut-off, defining the treatment and comparison municipalities.

The DD estimator of the child care expansion on maternal employment can be defined as

$$
E\left[Y_{1979}-Y_{1976} \mid \text { Young }=1, \text { Treated }=1\right]-E\left[Y_{1979}-Y_{1976} \mid \text { Young }=1, \text { Treated }=0\right]
$$


where $E$ is the expectations operator, $Y$ is a dichotomous dependent variable equal to 1 if the mother works (and 0 otherwise), Young is a dummy variable equal to 1 if the youngest child of the mother is between 3 and 6 years old (and 0 otherwise), and Treated is a dummy variable equal to 1 if the mother lives in a treatment area (and 0 is she lives in a comparison area).

The corresponding DD regression, estimated by OLS over the sample of mothers with the youngest child between 3 and 6 years old, can be defined as

$$
Y_{i t}=\beta_{0}+\beta_{1} \text { Treated }_{i}+\beta_{2} \text { Post }_{t}+\beta_{3} \text { Treated }_{i} \cdot \text { Post }_{t}+X_{i t}^{\prime} \zeta+\epsilon_{i t}
$$

where $i$ indexes mother, $t$ indexes year (1976 or 1979), Post is a dummy variable equal to 1 when $t=$ 1979 and 0 when $t=1976$, and $X$ is a vector of controls for child and parental characteristics. In our baseline specification, we include in $X$ dummy variables for the child's sex, the mother's and her spouse's age, years of education and immigrant status, number of older siblings by age, and for moving between municipalities within treatment/comparison areas. We also include municipality-specific fixed-effects and the local employment rate of prime age males to capture potentially differing labor market environment. As parental education may be endogenous to the policy changes, we measure educational attainment before the reform. The error term $\epsilon_{i t}$ is clustered on the mother, allowing for dependence in the error terms. ${ }^{12}$

The parameter of interest $\beta_{3}$ gives the average impact on mothers who reside in the treatment area in the post-reform period, of the additional child care slots following the reform in the treatment municipalities compared to the comparison municipalities. There are two types of averaging underlying this average causal effect. First, there is averaging over the impacts on children from different municipalities in the treatment area. And second, there is averaging across the marginal effects of the additional child care slots. For ease of interpretation, we will also report the percentage points increase in maternal employment rate per percentage point increase in child care coverage, defined as $\beta_{3}$ divided by the increase in child care coverage rate in the treatment area relative to the comparison area.

The DD approach controls for unobserved differences between mothers in different years as well as between mothers from treatment and comparison municipalities in the same year. The identifying assumption is that the growth rate in maternal employment before and after the reform would have been the same in the treatment municipalities as in the comparison municipalities, in the absence of the reform. If, for instance, child care expanded most in municipalities where it maternal employment was most responsive, then this would not pose a threat to identification of $\beta_{3}$. However, a concern could be that the growth in maternal employment differs by, say, education level, while there are systematic differences in educational attainment between mothers from treatment and comparison municipalities. To address such concerns for selection bias, we estimate equation (1) with and without the set of controls $X$.

Because we also control for municipality-specific fixed effects, it is not necessary that the child care expansion is unrelated to municipality characteristics. It is useful, however, to understand the determinants of the expansion across municipalities. In Section 5, we investigate this closely, finding that the characteristics of treatment and comparison municipalities are fairly similar in terms of political and demographic composition as well as local government expenditure and income. A notable exception is that the expansion was strongest in municipalities with the lowest ratio of formal child care coverage to employment rate of mothers with children in child care age. This conforms well to intuition, since federal subsidy rates were higher for municipalities with low child care coverage prior to the reform, but also because the local political pressure for expansion of formal care is likely to be stronger in areas where child care was severely rationed.

Although municipality-specific fixed effects picks up the direct effects of pre-determined and timeinvariant factors of the municipalities, like differences in rationing of formal child care prior to the reform, we may worry about the determinants of the child care expansion being systematically related to underlying trends in maternal employment. And even though the DD approach controls for unobserved differences both

\footnotetext{
${ }^{12}$ As maternal employment is a limited dependent variable, our linear probability model will be the best least-squares approximation of the true conditional expectation function. As noted by Angrist (2001), if there are no covariates or they are discrete, as in our case, linear models are no less appropriate for limited dependent variables than for other types of dependent variables. In any case, we have checked that our results are robust to alternative approximations of the conditional expectation function, estimating Logit and Probit models.
} 
between mothers in different years as well as between mothers from treatment and comparison municipalities in the same year, there could be changes over time in the differences in the unobservable characteristics of mothers from the two groups. As always in policy evaluation using non-experimental data we cannot completely guard against omitted variables bias. Yet to increase the confidence in our identification strategy, we run a battery of specification checks.

Specification checks. The assumption of a common time trend between the treatment and comparison group in the absence of the reform, is supported by the fact that we find no effects of a placebo reform, pretending that the child care expansion took place in the pre-reform period. Further, we take advantage of having access to panel data, restricting the sample to the same mothers before and after the reform. This removes biases due to unobserved compositional changes over time within the treatment group. By including individual-specific fixed effects, we also eliminate biases owing to permanent unobserved differences between mothers residing in treatment and comparison areas. In addition, we take several steps to make sure that selective migration of mothers into treatment and comparison areas is not driving our results.

Nevertheless, a concern with equation (1) is that changes specific to the treatment areas coinciding with the policy changes will bias our estimate of $\beta_{3}$. If, for instance, there are economic fluctuations specific to the treatment group that are not fully accounted for by local employment rates, the DD estimator may be biased. A similar problem would arise if the treatment municipalities also initiated other policies affecting maternal labor supply (although we found no evidence of such policies). We address this concern by adding mothers with the youngest child just above child care age ( 7 to 10 years old) as a second comparison group. This gives us a tripe-difference (DDD) estimator, exploiting that the child care reform creates variation along three dimensions: (a) between mothers with 3 to 6 year olds and 7 to 10 year olds; (b) between time periods before and after the reform; (c) between treatment areas and comparison areas. The additional comparison group should pick up time-varying effects specific to the treatment area, and correct for sources of bias mentioned above, since mothers of 7 to 10 year olds are unaffected by the reform.

The DDD estimator of the effect of the child care expansion on maternal employment can be defined as

$$
\begin{gathered}
\left\{E\left[Y_{1979}-Y_{1976} \mid \text { Young }=1, \text { Treated }=1\right]-E\left[Y_{1979}-Y_{1976} \mid \text { Young }=1, \text { Treated }=0\right]\right\} \\
-\left\{E\left[Y_{1979}-Y_{1976} \mid \text { Young }=0, \text { Treated }=1\right]-E\left[Y_{1979}-Y_{1976} \mid \text { Young }=0, \text { Treated }=0\right]\right\}
\end{gathered}
$$

where Young, as before, is equal to 1 if the youngest child of the mother is between 3 and 6 years old, and 0 if the youngest child of the mother is between 7 and 10 years old. The first curly brackets compares the expected growth rate in employment of mothers with the youngest child aged 3 to 6 years who live in treatment areas, with the expected growth rate for mothers with children of the same age living in the comparison areas. The second curly brackets makes the same comparison for mothers with slightly older children. The identifying assumption is that, on average, the difference between the employment rate of mothers with 3 to 6 year olds and mothers with 7 to 10 year olds would have changed similarly in treatment and comparison areas, in the absence of the reform.

The corresponding DDD regression, estimated by OLS over the sample of mothers with the youngest child 3 to 10 years old, can be expressed as

$$
\begin{aligned}
Y_{i t}= & \gamma_{0}+\gamma_{1} \text { Treated }_{i}+\gamma_{2} \text { Young }_{i t}+\gamma_{3} \text { Treated }_{i} \cdot \text { Young }_{i t} \\
& +\left[\gamma_{4}+\gamma_{5} \text { Treated }_{i}+\gamma_{6} \text { Young }_{i t}+\gamma_{7} \text { Treated }_{i} \cdot \text { Young }_{i t}\right] \text { Post }_{t}+X_{i t}^{\prime} \eta+\nu_{i t}
\end{aligned}
$$

It should be noted that the DDD regression, like the DD regression, allows for different intercepts by residency $\left(\gamma_{1}\right)$, as well as by child age $\left(\gamma_{2}\right)$ and their interaction $\left(\gamma_{3}\right)$. In addition, equation $(2)$ controls for changes coinciding with the reform, both in general $\left(\gamma_{4}\right)$, by residency $\left(\gamma_{5}\right)$ and by child age $\left(\gamma_{6}\right)$.

Above, we defined the treatment and comparison areas by ordering the municipalities according to the increase in child care coverage, and then separating them at the median. A concern is that our results are sensitive to this choice of treatment definition. Figure A1 reported in Appendix A draws histograms of the 
distributions of municipalities by child care coverage rate in 1976 and 1979. It shows a fairly good coherence in child care coverage rates between the treatment and comparison municipalities before the reform, and a striking difference after the reform. It is also evident that the treatment intensity varies within the two groups of municipalities. In the robustness analysis, we consider variations in the treatment intensity by changing the child care coverage cut-off defining the treatment and comparison municipalities. In addition, we follow Berlinski and Galiani (2007) in regressing maternal employment status on child care coverage rate in each municipality, controlling for time-specific and municipality-specific fixed effects, as well as a set of controls. This regression model, estimated by OLS over the sample of mothers with the youngest child between 3 and 6 years old, is given by

$$
Y_{i t}=\lambda \text { Post }_{t}+\psi C C_{i t}+X_{i t}^{\prime} \varphi+\varepsilon_{i t}
$$

where $C C_{i t}$ is the average child care coverage (in percent) in the municipality of child $i$ from the year $t$ when the child turns 3 years old until, but not including, year $t+4$ when he or she turns 7 and starts primary school. The parameter of interest $\psi$ gives the percentage point increase in maternal employment rate per percentage point increase in child care coverage.

\section{Data}

Our data are based on administrative registers from Statistics Norway covering the entire resident population of Norway from 1967-2006. The data contain unique individual identifiers that allow us to match each mother with her spouse and children. As we observe children's date of birth, we are able to construct an indicator for the age of the youngest child. The family and demographic files are merged through the unique individual identifiers with data on annual earnings based on information from the National Insurance administration and tax records. In addition, we add data on educational attainment, which are based on annual reports from Norwegian educational establishments. The information on municipality of residency and immigration status is from the Central Population Register, which is updated annually by local population registers.

Importantly, we also have administrative register data on all formal child care institutions and their location from 1972, reported directly from the institutions themselves to Statistics Norway. All licensed care givers are required to report annually the number of children in child care by age. Merging this data with the demographic files containing information about the total number of children according to age and residency, we construct a time series of annual child care coverage (by age of child) in each of the 418 municipalities. The coverage and reliability of Norwegian register data is considered to be exceptional, as is documented by the fact that they received the highest rating in a data quality assessment conducted by Atkinson et al. (1995).

To define our population of study, we start with the entire population of Norwegian mothers with the youngest child between 3 and 10 years of age in either 1976 or 1979 . In each year, we exclude mothers who were younger than 20 years or older than 55 years, as well as mothers currently in education, since it is difficult to assess their labor force status. To avoid migration induced by the child care reform, we also exclude a small fraction of mothers who move between treatment and comparison municipalities from 1976 to 1979 . The sample then consists of 507,751 observations. Finally, we restrict the sample to married mothers, which makes up 90 percent of the above sample. The reason for this choice is that our family data do not allow us to distinguish between cohabitants and single parents in these years. Rather than dropping observations where information on the husband's education is missing, we include a separate category for missing values. The number of older siblings relates to children born to each mother. The final sample used in the estimations consists of 455,559 observations, of which 252,699 had the youngest child between 3 and 6 years old (121,517 in 1979, and 131,182 in 1976). When interpreting our results, it is necessary to keep in mind that we focus on married mothers. Thus, our results do not speak to the literature on child care policies targeting single mothers, who are also not the central focus of the policy debates on universal child care. 
Table 2: Descriptive statistics of mothers with the youngest child 3 to 6 years of age

\begin{tabular}{|c|c|c|c|c|c|c|}
\hline & \multicolumn{2}{|c|}{ Treated, 1976} & \multicolumn{2}{|c|}{$\begin{array}{l}\text { Diff. in means } \\
\text { Treat. - Comp. }\end{array}$} & \multicolumn{2}{|c|}{$\begin{array}{c}\text { Normalized diff. } \\
\text { Treat. - Comp. }\end{array}$} \\
\hline & Mean & $\mathrm{SD}$ & 1976 & 1979 & 1976 & 1979 \\
\hline \multicolumn{7}{|l|}{ Dependent variables } \\
\hline Maternal employment & 0.2452 & 0.4302 & 0.0258 & 0.0341 & 0.0305 & 0.0374 \\
\hline Full time equivalent & 0.0892 & 0.2851 & 0.0152 & 0.0237 & 0.0277 & 0.0409 \\
\hline \multicolumn{7}{|l|}{ Control variables } \\
\hline Employment rate & 0.8682 & 0.0404 & -0.0004 & 0.0003 & -0.005 & 0.0043 \\
\hline Age & 32.30 & 5.65 & 0.2518 & 0.3198 & 0.0221 & 0.0301 \\
\hline Husband's age & 35.17 & 6.89 & 0.0896 & 0.1961 & 0.0065 & 0.0152 \\
\hline Education (years) & 9.93 & 2.09 & 0.2838 & 0.2814 & 0.0702 & 0.0689 \\
\hline Husband's edu. (years) & 10.69 & 2.84 & 0.3903 & 0.3868 & 0.0711 & 0.0711 \\
\hline Children $3-6$ y.o. & 1.2136 & 0.4098 & -0.0042 & -0.0011 & -0.0051 & -0.0014 \\
\hline Children $7-10$ y.o. & 0.5919 & 0.6471 & -0.0182 & -0.0245 & -0.014 & -0.0198 \\
\hline Children $11-15$ y.o. & 0.3481 & 0.632 & -0.0361 & -0.036 & -0.028 & -0.0291 \\
\hline Immigrant & 0.0387 & 0.193 & 0.0085 & 0.0096 & 0.0234 & 0.0264 \\
\hline Relocated & 0.0455 & 0.2083 & 0.0028 & 0.0067 & 0.0069 & 0.0165 \\
\hline \multirow[t]{3}{*}{ Sample size } & & \multicolumn{2}{|c|}{ Treated } & \multicolumn{2}{|c|}{ Comparison } & \\
\hline & & 1976 & 1979 & 1976 & 1979 & \\
\hline & & 62,236 & 57,675 & 68,946 & 63,842 & \\
\hline
\end{tabular}

${ }^{*} p<0.10,{ }^{* *} p<0.05,{ }^{* * *} p<0.01$ (one-tailed)

Notes: Treatment (comparison) municipalities are above (below) the median in child care coverage growth from 1976 to 1979. Outcome and control variables are defined in Section 5. Standard deviations are denoted SD, and normalized differences are defined as differences in averages by treatment status, scaled by the square root of the sum of variances.

Unfortunately, we do not have data on hours of work. To measure labor market attachment, we therefore rely on information about annual earnings, including wages and income from self-employment. Specifically, we construct dummy variables for employment and full-time equivalent status based on the basic amount thresholds of the Norwegian Social Insurance Scheme (used to define labor market status, determining eligibility for unemployment benefits as well as disability and old age pension). In 2006, one basic amount is about USD 10,500. A mother is defined as employed if she earns more than two basic amounts, and working full-time if she has more than four basic amounts in earnings. As shown below, our results are robust to how we set the thresholds determining employment and full-time equivalent status.

\subsection{Descriptive statistics}

Table 2 shows descriptive statistics for our dependent variables and the set of controls for mothers with the youngest child between 3 and 6 years of age. We see that about a quarter of the mothers in the treatment group in 1976 were working, and slightly less than 9 percent were in full-time employment. It is also evident that there are modest differences in the labor market status of the treatment and comparison group, both before and after the reform. In a DD framework, this pattern is suggestive of little impact of child care on maternal labor supply.

Our DD approach identifies the effects of child care by comparing the change in employment rates before and after the reform of mothers residing in treatment and comparison areas. Substantial changes over time in the differences in the observable characteristics of the two groups may suggest unobserved compositional changes, calling our empirical strategy into question. Table 2 shows that the treatment and comparison groups have fairly similar characteristics. More importantly, there appears to be hardly any changes over time in the relative characteristics of the two groups. Table A2 in Appendix A examines this further, 
reporting DD estimates of equation (1), where we have replaced the dependent variable with each control variable. The results show negligible - and often insignificant - differences over time in the characteristics of mothers residing in the treatment and comparison areas. The same picture holds true for mothers with the youngest child between 7 and 10 years old, which we use as a second comparison group in the DDD regressions. Table A1 provided in Appendix A reports descriptive statistics for our dependent variables and the set of controls for mothers with the youngest child between 7 and 10 years of age.

A concern in applying linear regressions is lack of overlap in the covariate distribution. As emphasized by Imbens and Wooldridge (2009), this can be assessed by the (scale-invariant) normalized difference measure. For each covariate, the normalized difference is defined as the difference in averages by treatment status, scaled by the square root of the sum of variances. Imbens and Wooldridge suggest as a rule of thumb that linear regression methods tend to be sensitive to the functional form assumption if the normalized difference exceeds one quarter. Table 2 also displays normalized differences for our controls in the final two columns, indicating that lack of overlap should be of little concern for the estimated effects. This also holds true for the set of controls for mothers with the youngest child between 7 and 10 years of age, as shown in Table A1 presented in Appendix A.

Because we control for municipality-specific fixed effects, it is not necessary that the child care expansion is unrelated to municipality characteristics. However, if determinants of the expansion are systematically related to underlying trends in maternal employment, we may be worried about differences in the characteristics of treatment and comparison municipalities. It is useful, therefore, to understand the determinants of the expansion across municipalities.

In Appendix A, we include a map of Norway, marking the treatment and comparison municipalities in Figure A2. The map shows that the municipalities are reasonably well spread out, covering urban and rural municipalities. In our baseline specification, five of the ten largest cities - by the number of children in our sample - are defined as treatment municipalities (Oslo, Bergen, Stavanger, Bærum and Fredrikstad), while the others are defined as comparison municipalities (Trondheim, Kristiansand, Troms $\varnothing$, Skien and Drammen). Further, Table A3 in Appendix A displays characteristics of the municipalities in the treatment and comparison area. There appears to be no substantial differences in terms of local government expenditure per capita, in total or on primary school in particular. This is most likely because of strict federal provisions for minimum standards of different local public services, and considerable ear-marked grants-in-aid from the central government. The same holds for local government income, consisting largely of grants-in-aid from the central government, in addition to local income taxes and user fees. This comes as no surprise, as the federal government determines the tax rate and the tax base of the income tax. Also, the federal government used equalization transfers to redistribute income from rich to poor municipalities, such that local differences in revenues are largely offset (Løken, 2009). Interestingly, there are no noticeable differences in the share of female voters between the municipalities of the treatment and comparison area, nor is there significant disparity in the socialist shares of voters. This conforms well to the fact that there was broad bipartisan support for child care expansion in Norway in the 1970s. Further, there are no substantial differences in population size or the population shares of neither 0 to 6 year olds, nor females of fecund age, 19-35 or $36-55$ years old.

There are, however, a couple of notable differences between treatment and comparison municipalities. Most importantly, the ratio of child care coverage to employment rate of mothers of 3-6 year olds prior to the reform, is substantially lower in treatment municipalities than in comparison municipalities. In treatment municipalities, there is on average more than four employed mothers for each child care place, while the same ratio is less than three-to-one in comparison municipalities. This conforms well to intuition, since federal subsidy rates were higher for municipalities with low child care coverage prior to the reform, but also because the local political pressure for expansion of formal care is likely to be stronger in areas where child care was severely rationed. We also see that two of the variables indicating rurality indicate a small positive relationship with the child care expansion (average distance to zone center and ear marks per capita). This might be due to the discreteness of child care expansion; Establishing a typical child care institution increases the child care coverage rate more in smaller than in larger municipalities. In Norway, there was a very slow process of urbanization until the mid 1980s (Berg, 2005), which implies that rurality status is likely to be more or less constant during the period we consider, and should, therefore, be picked 
Table 3: Main results

(1) (2) (3) (4)

Estimate

SE

Mean

(4)

(5)

(6)

\begin{tabular}{|c|c|c|c|c|c|}
\hline Estimate & $\mathrm{SE}$ & Mean & Estimate $/ \triangle C C$ & Controls & Mun. FE \\
\hline \multicolumn{6}{|c|}{ Panel A. Employment } \\
\hline $0.0083^{* * *}$ & 0.0035 & 0.2452 & $0.0467^{* * *}$ & No & No \\
\hline $0.0088^{* * *}$ & 0.0032 & 0.2452 & $0.0490^{* * *}$ & Yes & No \\
\hline $0.0111^{* * *}$ & 0.0032 & 0.2452 & $0.0624^{* * *}$ & Yes & Yes \\
\hline \multicolumn{6}{|c|}{ Panel B. Full time equivalent } \\
\hline $0.0085^{* * *}$ & 0.0023 & 0.0892 & $0.0477^{* * *}$ & No & No \\
\hline $0.0086^{* * *}$ & 0.0021 & 0.0892 & $0.0482^{* * *}$ & Yes & No \\
\hline $0.0097^{* * *}$ & 0.0021 & 0.0892 & $0.0542^{* * *}$ & Yes & Yes \\
\hline
\end{tabular}

${ }^{*} p<0.10,{ }^{* *} p<0.05,{ }^{* * *} p<0.01$ (one-tailed)

Notes: Estimations are based on OLS on equation (1). The controls are listed in Table 2. The dependent variables are defined in Section 5. The sample consists of 252,699 married mothers with the youngest child aged 3-6 years. $\Delta C C$ is defined as the increase in child care coverage following the reform in the treatment group relative to the comparison group. Mean refers to the pre-reform means in the treatment group. Standard errors (SE) are clustered on the mother and robust to heteroskedasticity.

up by the municipality-specific fixed effects. ${ }^{13}$

\section{Main empirical results}

This section presents our main results based on equation (1), suggesting that subsidized, universally accessible child care has hardly any effect on maternal employment. To address concerns for selection bias, we report estimates with and without the set of controls capturing important child and parental characteristics, as well as municipality-specific fixed effects. Estimates are quite similar across the different specifications and qualitatively the same. We use as our baseline specification the model including controls and municipality-specific fixed effects. All estimates are significant at the one percent level.

Table 3 shows our main results, both on employment (Panel (A)) and on the full-time equivalent status (Panel (B)). Starting with the extensive margin of maternal labor supply, the baseline specification (cf. Column (1), Row (3)) suggests a 1.1 percentage points increase in the employment rate from the 17.85 percentage points increase in child care coverage in the treatment area relative to the comparison area. While statistically significant, the 95 percent upper bound suggests that this child care expansion increased maternal employment rate by less than 1.8 percentage points. Using our point estimate, the treatment municipalities were able to induce less than 765 mothers to work by facilitating the supply of an additional 17,500 child care places. This corresponds to a .06 percentage points increase in maternal employment rate per percentage point increase in child care coverage (cf. Column (4), Row (3)).

While the decision to actually participate in the labor market seems to be at best marginally affected, the child care expansion could have had an impact on the probability of working full-time. For example, mothers who utilize formal child care may choose to work longer hours. The baseline specification (cf. Column (1), Row (6)) shows, however, that the child care reform increased the probability of full-time employment by as little as .97 percentage points. This corresponds to a .054 percentage points increase in mothers working full-time per percentage points increase in child care coverage (cf. Column (4), Row (6)). It should be noted that our results are robust to how we draw the thresholds determining employment and full-time equivalent status, as shown in Table A4 provided in Appendix A.

\footnotetext{
${ }^{13}$ We have also regressed the change in the municipality's child care coverage between 1976 and 1979 on the characteristics of the municipalities listed in Table A3. Consistent with the descriptive statistics, there is little evidence of systematic relationships between the child care expansion and most of these characteristics. Again, the most notable exception is the ratio of child care to maternal employment rate prior to the reform.
} 


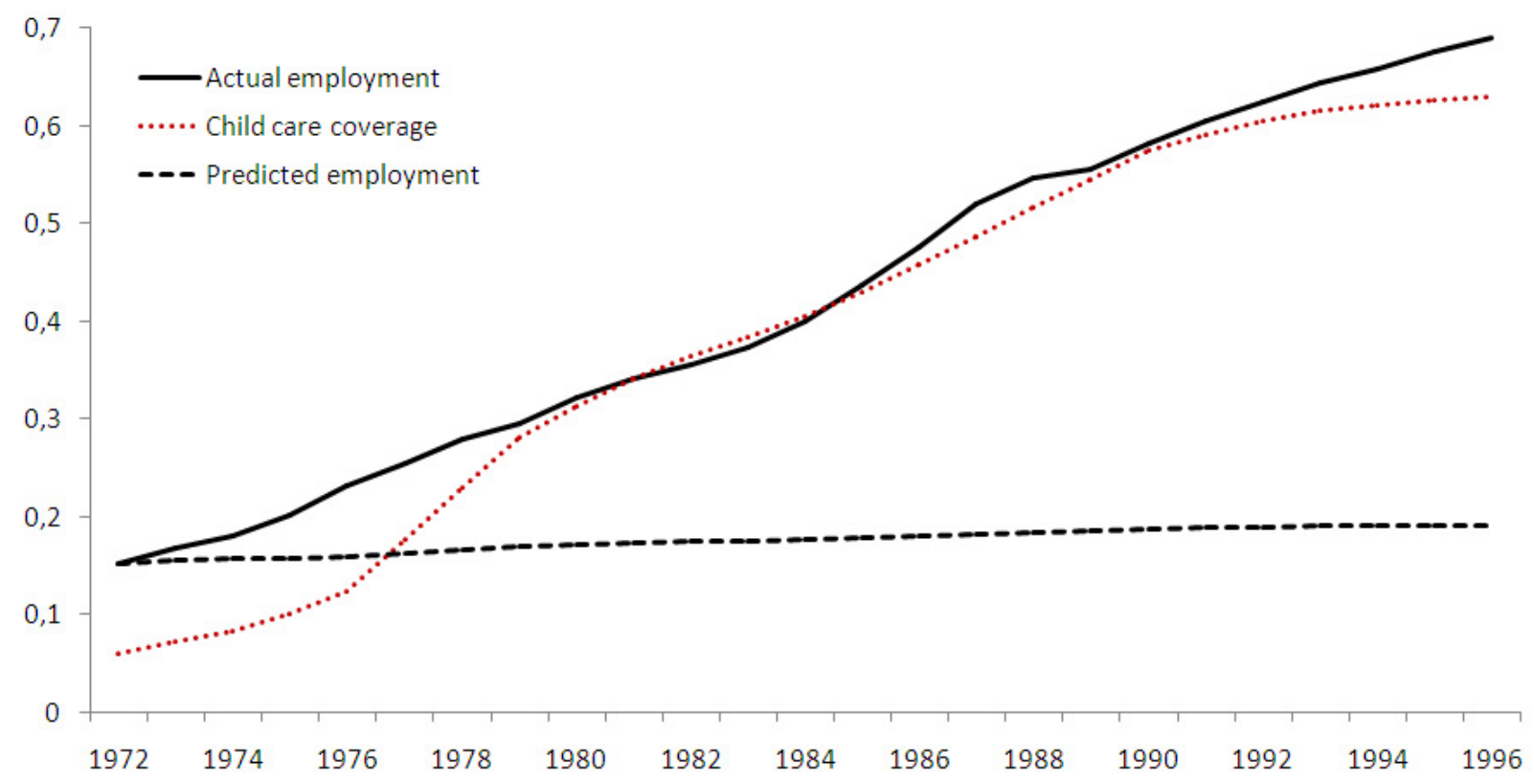

Figure 4: Actual and predicted employment rates for married mothers with youngest child 3 to 6 years old from growth in child care coverage

Notes: Employment is defined in Section 4. Child care coverage relates to children 3-6 years old. The baseline estimate used in the prediction can be found in Column 4 and Row 3 of Panel (A) in Table 3.

The estimated labor market response can be used to hone in on the extent to which the strong expansion in formal child care crowds out informal care arrangements. Following Blau and Currie (2006), consider the following three combination of mother's work and child care decision: not working and maternal care, working and informal care, and working and formal care. In this case, our finding of a 0.06 percentage points increase in maternal employment per percentage point increase in the child care coverage rate, can be interpreted as suggesting that the new subsidized formal child care was associated with a 94 percent crowding out of informal care, implying a significant net cost of the subsidies. ${ }^{14}$.

To put our results into perspective, consider Figure 4 showing the trends in child care coverage and employment rates of Norwegian mothers with the youngest child between 3 and 6 years old. In the figure, we use the estimate from our baseline specification in Panel (a) in Table 3 to draw the predicted maternal employment rate from the increase over time in child care coverage since 1972. Although our estimated child care effect may not be externally valid for later periods, Figure 4 at least serves as an illustration of how little the introduction of subsidized, universally accessible child care in Norway can explain of the rapid growth in maternal employment in the late 1970s. With this caveat in mind, the massive increase of 57 percentage points in child care coverage in Norway between 1972 and 1996 can explain less than 4 of the 55 percentage points rise in maternal employment over the period, despite the strong correlation. By the same token, cross-country differences in child care may only be able to account for a small fraction of the gap in maternal employment between Norway and other developed countries.

Turning to subsample analysis, we find no evidence of the very small mean impacts of the child care expansion on maternal employment being an artefact of positive and negative labor supply responses offsetting each other. Table 4 displays results from equation (1) including controls and municipality-specific fixed

\footnotetext{
${ }^{14}$ It is also possible that non-working mothers were taking up some of the new care child care slots. However, survey results reported in Leira (1992) suggests that the number of non-working mothers using formal child care did not increase over the period 1973-1985
} 
Table 4: Subsample estimations of child care on maternal employment

\begin{tabular}{lccccc}
\hline & $(1)$ & $(2)$ & $(3)$ & $(4)$ & $(5)$ \\
& Estimate & SE & Mean & Estimate/ $\Delta C C$ & $\mathrm{~N}$ \\
\hline Age 19-30 & $0.0102^{* * *}$ & 0.0044 & 0.2454 & $0.0572^{* * *}$ & 144,918 \\
Age 31-49 & $0.0115^{* *}$ & 0.005 & 0.2449 & $0.0646^{* *}$ & 107,781 \\
Attended high school & $0.0160^{* *}$ & 0.008 & 0.4579 & $0.0897^{* *}$ & 54,841 \\
No high school & $0.0090^{* * *}$ & 0.0035 & 0.1825 & $0.0505^{* * *}$ & 197,858 \\
1 child, 3-6 y.o. & $0.0093^{* * *}$ & 0.0037 & 0.2643 & $0.0521^{* * *}$ & 203,197 \\
2+ children, 3-6 y.o. & $0.0119^{* *}$ & 0.0068 & 0.1748 & $0.0666^{* *}$ & 49,502 \\
1-2 children, 3-15 y.o. & $0.0095^{* * *}$ & 0.004 & 0.2794 & $0.0532^{* * *}$ & 177,662 \\
3+ children, 3-15 y.o. & $0.0099^{* *}$ & 0.0056 & 0.168 & $0.0556^{* *}$ & 75,037 \\
No cities & $0.0110^{* * *}$ & 0.0035 & 0.2187 & $0.0561^{* * *}$ & 212,676 \\
\hline
\end{tabular}

${ }^{*} p<0.10,{ }^{* *} p<0.05,{ }^{* * *} p<0.01$ (one-tailed)

Notes: Estimations are based on OLS on equation (1), with the controls listed in Table 2 and municipality-specific fixed effects. The dependent variable employment is defined in Section 5. $\triangle C C$ is defined as the increase in child care coverage following the reform in the treatment group relative to the comparison group. Standard errors (SE) are clustered on the mother and robust to heteroskedasticity. Mean refers to the pre-reform means in the treatment group, and $\mathrm{N}$ denotes sample size. Attended high school is defined as completed education of at least 10 years. No cities excludes mothers from the 3 big cities (Oslo, Bergen and Trondheim).

effects, when estimated separately by age, educational attainment, and number of children of the mother. We see that the subsample estimates are remarkably similar to our baseline estimate of .011, and never significantly different. As expected, the point estimate for mothers with higher educational attainment is somewhat larger. It should be noted that we cannot tell whether that is due to differences in child care take-up or heterogeneous impacts of uptake, as we unfortunately do not have data on child care use by child and parental characteristics. Further, to make sure that our results are not driven by secular changes between urban and rural areas coinciding with the reform, Table 4 also presents estimates where we have dropped the three largest cities (Oslo, Bergen, and Trondheim) from the sample. The estimated child care effect barely moves. Subsample results for full-time equivalent employment are similar, though mothers with fewer young children respond somewhat stronger on this margin, and the difference depending on education is more pronounced.

\section{Specification checks}

Table 5 reports results from a battery of specification tests, demonstrating that the effect of child care on maternal employment are very similar across the different specifications and qualitatively the same. This also hold true for full-time employment, but we omit the results for brevity.

Time trend. Our DD approach identifies the child care effects from the assumption of a common time trend in the treatment and comparison group in the absence of the reform. A concern is that our positive effects may reflect differential time trends between the treatment and comparison municipalities, rather than a true policy impact. To investigate this, we estimate the effects of a placebo reform, pretending that the child care expansion took place in the pre-reform period. Panel (D) in Table 5 reports the placebo reform effect, from estimating equation (1) on the sample of married mothers with the youngest child between 3 and 6 years old in 1972 and/or 1975 . In this case, the variable Post is equal to 1 when $\mathrm{t}=1975$ and 0 when t $=$ 1972. If there were differential secular time trends in the treatment and comparison municipalities, then the estimated effect of the placebo reform should be significantly different from zero. By contrast, the estimated placebo reform effect is virtually zero and insignificant. 
Table 5: Specification checks

\begin{tabular}{|c|c|c|c|c|c|}
\hline & $\begin{array}{c}(1) \\
\text { Estimate }\end{array}$ & $\begin{array}{l}(2) \\
\mathrm{SE}\end{array}$ & $\begin{array}{c}(3) \\
\text { Mean }\end{array}$ & $\begin{array}{c}(4) \\
\text { Estimate } / \triangle C C\end{array}$ & $\begin{array}{l}(5) \\
\mathrm{N}\end{array}$ \\
\hline \multicolumn{6}{|c|}{ Panel A. Alternative treatment definitions } \\
\hline 1976-1979 (33rd/67th) & $0.0147^{* * *}$ & 0.0046 & 0.2354 & $0.0499^{* * *}$ & 132,319 \\
\hline 1976-1978 (50th/50th) & $0.0062^{* *}$ & 0.0031 & 0.2437 & $0.0434^{* *}$ & 258,808 \\
\hline 1977-1979 (50th/50th) & $0.0052^{*}$ & 0.0033 & 0.2726 & $0.0448^{*}$ & 252,932 \\
\hline $1977-1980(50 \operatorname{th} / 50 \operatorname{th})$ & $0.0057^{*}$ & 0.0035 & 0.2417 & $0.0382^{*}$ & 249,091 \\
\hline Linear in child care & $0.0016^{* * *}$ & 0.0001 & 0.2452 & - & 252,699 \\
\hline \multicolumn{6}{|l|}{ Panel B. Panel data estimation } \\
\hline No covariates & 0.0058 & 0.005 & 0.2065 & 0.0326 & 51,392 \\
\hline Controls and mun. FE & $0.0104^{* *}$ & 0.0051 & 0.2065 & $0.0581^{* *}$ & 51,392 \\
\hline Controls, mun. FE and ind. FE & $0.0095^{* *}$ & 0.0051 & 0.2065 & $0.0531^{* *}$ & 51,392 \\
\hline \multicolumn{6}{|l|}{ Panel C. Triple-differences } \\
\hline No covariates & $0.0114^{* *}$ & 0.0055 & 0.2757 & $0.0641^{* *}$ & 455,559 \\
\hline Controls & $0.0135^{* * *}$ & 0.0052 & 0.2757 & $0.0759^{* * *}$ & 455,559 \\
\hline Controls and mun. FE & $0.0126^{* * *}$ & 0.0051 & 0.2757 & $0.0707^{* * *}$ & 455,559 \\
\hline \multicolumn{6}{|c|}{ Panel D. Other specification checks } \\
\hline Placebo reform & -0.0018 & 0.003 & 0.145 & -0.01 & 202,860 \\
\hline Cluster: Mun $\times$ Period & $0.0111^{* * *}$ & 0.003 & 0.2452 & $0.0624^{* * *}$ & 252,699 \\
\hline Selective migration & $0.0099^{* * *}$ & 0.0033 & 0.2446 & $0.0552^{* * *}$ & 249,815 \\
\hline
\end{tabular}

${ }^{*} p<0.10,{ }^{* *} p<0.05,{ }^{* * *} p<0.01$ (one-tailed)

Notes: The controls are listed in Table 2, and the dependent variable is defined in Section 5. $\triangle C C$ is defined as the increase in child care coverage following the reform in the treatment group relative to the comparison group. Standard errors (SE) are clustered on the mother and robust to heteroskedasticity. Mean refers to the pre-reform means in the treatment group, and $\mathrm{N}$ denotes sample size. Panel $A$ : In rows 1-4, estimates are based on equation (1), with controls and municipalityspecific fixed effects. In rows 1-4, the expansion periods are 1976-1979, 1976-1978, 1977-1979 and 1977-1980, respectively. In Row 1, treated municipalities are over the 67th percentile and comparison municipalities are below the 33rd percentile in child care coverage growth, whereas the cut-off is at the median in rows $2-4$. In row 5 , the estimate is based on equation (3), assuming a linear relationship between maternal employment and child care coverage. Panel B: Estimates are based on (1), applied to the subsample of mothers with 3-year olds in 1976. Rows 1 and 2 report estimates from this sample with and without controls and municipality-specific fixed effects. Row 3 adds individual-specific fixed effects. Panel C: Estimates are based on equation (2), including mothers with 3-6 year old and 7-10 year olds in the estimation sample. Panel D: Row 1 reports results from equation (1) with controls and municipality-specific fixed effects, applied to the sample of mothers with 3-6 year olds in 1972 and 1975. Row 2 reports results from equation (1) with controls and municipality-specific fixed effects, clustering standard errors to account for serial dependence of the errors within municipality-period groups. Row 3 reports results from equation (1), where mothers' municipality of residency in 1973 are used to determine whether they belong to the treatment or comparison municipalities. 
Nevertheless, our estimates could be biased if treatment municipalities initiated other policies (that we are unaware of) or experienced different economic fluctuation (that are not fully accounted for by the local employment rates) at the same time as the child care reform. To pick up such time-varying effects specific to the treatment area, equation (2) adds mothers with the youngest child just above the child care age ( 7 to 10 years old) as a second comparison group. It is heartening to find in Panel (C) in Table 5 that this tripledifference approach produces very similar estimates of the child care effects on maternal employment. This holds true when we estimate the DDD regression without any covariates, with controls, and with controls and municipality-specific fixed effects.

Clustering. To account for the fact that the variation in the data we use to estimate the child care effects is at the municipality-period level, Row (2) in Table 5 reports results from our baseline specification, clustering the standard errors at this level. By doing so, we allow for period-specific shocks that are common to mothers who live in the same municipality. We find that accounting for dependence within municipalityperiod groups does not increase our estimated standard errors much, and the significance levels of the results are very similar. ${ }^{15}$

Selective migration. Although location decisions based on unobservable characteristics may affect our estimates, the direction of the bias is not obvious. ${ }^{16}$ On the one hand, mothers inclined to work may be more likely to move to municipalities with high child care coverage rates. On the other hand, mothers unwilling to work because they have children who need special attention or supervision, may be more inclined to move to municipalities with good access to child care. Though recent empirical work finds little support for such Tiebout sorting across states or municipalities according to public good provision like school quality, ${ }^{17}$ we take several steps to avoid that selective migration of mothers into treatment and comparison municipalities confounds our results.

To address the concern for in-migration induced by the reform, we excluded in our main analysis mothers that move between treatment and comparison municipalities from 1976 to 1979. In addition, we control for relocation between municipalities within the treatment and comparison areas, respectively; We have also performed all estimations excluding mothers that relocate, and the results are unchanged. However, one could argue that even the sample of stayers is selective, as out-migration could be endogenous to the child care expansion. To address this issue, we use the mothers' municipality of residency in 1973 to determine whether they belong to treatment or comparison municipalities. Panel (D) shows that the effects of the child care expansion on maternal employment is robust to using municipality of residency several years before the reform to determine treatment status. This finding conforms well with the results from Hægeland et al. (2008), which suggest that school quality matters little, if anything, for location decisions in Norway.

Alternative treatment definitions. In our baseline specification, we define the treatment and comparison areas by ordering municipalities according to the increase in child care coverage rate in the period 19761979, and then separating them at the median. In Panel (A) in Table 5, we make sure that our results are not artifacts of this choice of treatment definition. As the expansion in child care varies across treatment definition we need to focus on Column (4), showing the percentage points increase in maternal employment per percentage point increase in the child care coverage rate.

In the first row of Panel (A), we use the same time-interval, but divide the sample at the 33rd and 67th percentiles of child care growth. Municipalities below the lower threshold are in the comparison group, while those above the upper threshold are in the treatment group. Mothers residing in municipalities between the two thresholds are excluded from the sample used for estimation. In the three next rows, we define the

\footnotetext{
${ }^{15}$ Bertrand et al. (2004) show that the standard errors in DD regressions may be misstated if there is serial correlation in the municipality-period shocks. As their analysis demonstrates, we reduce the problem of serial correlation considerably by collapsing the time-series dimension into two periods: before and after the reform.

${ }^{16}$ Note that families living on the municipal borders could not take advantage of the child care expansion in neighboring municipalities without relocating, since eligibility was based on municipality of residency.

${ }^{17}$ See e.g. Rhode and Strumpf (2003) who find little support for Tiebout sorting across municipalities and counties using about 150 years of data.
} 
treatment and comparison status according to the median child care growth, but alter the time-interval. For example, the second row takes 1978 to be the post-reform period. Our findings show that the percentage points increase in maternal employment per percentage point increase in the child care coverage rate is quite similar across treatment definitions. More importantly, the results confirm the picture of almost no effect of the introduction of subsidized, universally accessible child care on maternal employment.

To sidestep the issue of how to draw the line between treatment and comparison municipalities we estimate equation (3), where maternal employment is regressed on child care coverage in each municipality, controlling for time-specific and municipality-specific fixed effects as well as the set of controls. The last row in Panel (A) reports the child care estimate from this regression, suggesting less than a .002 percentage points increase in maternal employment rate per percentage point increase in child care coverage. This confirms the picture of hardly any child care effect.

Panel data estimation. In this final specification test, we restrict our sample to mothers whose youngest child is 3 years old in 1976, observed both before and after the reform with a child in child care age. This removes biases due to unobserved compositional changes over time within the treatment group. By including individual-specific fixed effects, we also eliminate biases owing to permanent unobserved differences between mothers residing in treatment and comparison areas. The child care effect is then identified from changes in the employment rate of the same mothers over time, experiencing different exposure to child care in the different periods. Panel (B) in Table 5 shows that these specification checks barely move the estimated child care effects on maternal employment.

\section{Concluding remarks}

There is a heated debate in the US and Canada, as well as in many European countries, about a move towards subsidized universally accessible child care or pre-school. Advocates of such policies have argued that good access to affordable child care is important to facilitate female labor force participation and lower welfare dependency. Indeed, generous child care policies are regularly proposed as a key determinant both of cross country differences in maternal employment (see e.g. Jaumotte, 2003; Del Boca, 2002; Aaberge et al. 2005), and of its dramatic growth over the last decades (see e.g. Attanasio et al., 2008). Our finding of hardly any causal effect of child care on maternal employment, suggests that we need to be cautious when making such a conclusion. Instead of increasing mothers' labor supply, the introduction of subsidized, universally accessible child care in Norway mostly crowded out informal care arrangements, implying a significant net cost of the child care subsidies. Our study therefore serves as an illustration of how publicly funded services replace what would have been purchased in other, more decentralized ways, and without the associated tax burdens.

Apparently, our results also provide empirical support to Rosen's (1996) controversial and widely discussed claim that the child care subsidies in Scandinavian countries are too large. However, the debate on universal child care systems cannot be restricted to an analysis of labor market responses to changes in work incentives; other considerations also come into play. In particular, recent research from a number of fields suggests that investments in early childhood have high returns, especially for disadvantaged children (Knudsen et al., 2006). On this background, Currie (2001) argues that governments should aim to equalize initial endowments through early childhood development, rather than compensate for differences in outcomes later in life. The role of governments in facilitating child development is particularly important, both from positions on equity and efficiency, if families under-invest in early childhood due to market failures such as liquidity constraints, information failures, and externalities (Gaviria, 2002). Havnes and Mogstad (2009) study the same child care reform as we do, but address the impact on children's long-run outcomes. The results obtained in this analysis suggest that universally accessible child care improves the long-run prospects of children considerably, echoing previous evidence from intensive early intervention programs in the US that were targeting particularly disadvantaged children (see e.g. Karoly et al., 2005). Consequently, we cannot conclude that the child care subsidies offered in Scandinavian countries are too large, but the pivotal argument must rely on other aspects than increased maternal employment, such as improved child development. 


\section{Acknowledgements}

Thanks to Rolf Aaberge, Erling Barth, Nabanita Datta Gupta, Hilary Hoynes, Halvor Mehlum, Kalle Moene, Mari Rege, Terje Skjerpen, Mark Votruba, and a number of seminar and conference participants for useful comments and suggestions. Financial support from the Norwegian Research Council (194339) is gratefully acknowledged. The project is also part of the research activities at the ESOP center at the Department of Economics, University of Oslo. ESOP is supported by The Research Council of Norway. 
[1] Aaberge, R., U. Colombino, D. D. Boca, J. Ermisch, M. Francesconi, S. Pasqua, And S. Strøm (2005): "Part II: Women's Participation in the Labor Market and Fertility: The Effects of Social Policies," in Labor Market Participation and Fertility of Women: the Effect of Social Policies, ed. by T. Boeri, D. Del Boca, and C. Pissarides, pp. 121-264. Oxford University Press, UK.

[2] Angrist, J. D. (2001): "Estimations of Limited Dependent Variable Models with Dummy Endogenous Regressors: Simple Strategies for Empirical Practice: Reply," Journal of Business ES Economic Statistics, 19(1), 27-28.

[3] Atkinson, A. B., L. Rainwater, AND T. M. Smeeding (1995): Income distribution in OECD countries : evidence from the Luxembourg Income Study. OECD Publications and Information Center, Paris.

[4] Attanasio, O., H. Low, And V. Sanchez-Marcos (2008): "Explaining Changes in Female Labor Supply in a Life-Cycle Model," American Economic Review, 98(4), 1517-1552.

[5] Baker, M., J. Gruber, And K. Milligan (2008): "Universal Child Care, Maternal Labor Supply, and Family Well-Being," Journal of Political Economy, 116(4), 709-745.

[6] BERG, P. (2005): "Ulik respons på fraflytting og sentralisering," Statistiske Analyser 69, Statistics Norway.

[7] Berlinski, S., AND S. Galiani (2007): "The effect of a large expansion of pre-primary school facilities on preschool attendance and maternal employment," Labour Economics, 14(3), 665-680.

[8] Bertrand, M., E. Duflo, And S. Mullainathan (2004): "How Much Should We Trust Differences-in-Differences Estimates?," The Quarterly Journal of Economics, 119(1), 249-275.

[9] Besley, T., AND A. CASE (2000): "Unnatural Experiments? Estimating the Incidence of Endogenous Policies," Economic Journal, 110(467), F672-F694.

[10] Blau, D. M., AND J. Currie (2006): "Pre-School, Day Care, and After-School Care: Who's Minding the Kids?," in Handbook of the Economics of Education, ed. by E. A. Hanushek, and F. Welch, vol. 2, pp. 1163-1278. Elsevier.

[11] Blau, D. M., AND P. K. Robins (1988): "Child-Care Costs and Family Labor Supply," The Review of Economics and Statistics, 70(3), 374-381.

[12] Boeri, T., D. Del Boca, AND C. Pissarides (eds.) (2005): Labor Market Participation and Fertility of Women: the Effect of Social Policies. Oxford University Press, UK.

[13] Cascio, E. (2006): "Public Preschool and Maternal Labor Supply: Evidence from the Introduction of Kindergartens into American Public Schools," Discussion Paper 05, University of Kentucky Center for Poverty Research.

[14] — (2009): "Maternal Labor Supply and the Introduction of Kindergartens into American Public Schools," Journal of Human Resources, 44, 140-170.

[15] Connelly, R. (1992): "The Effect of Child Care Costs on Married Women's Labor Force Participation," The Review of Economics and Statistics, 74(1), 83-90.

[16] Currie, J. (2001): "Early Childhood Education Programs," Journal of Economic Perspectives, 15(2), 213-238.

[17] Del BocA, D. (2002): "The Effect of Child Care and Part Time Opportunities on Participation and Fertility Decisions in Italy," Journal of Population Economics, 15, 549-573.

[18] Dolado, J. J., F. Felgueroso, And J. F. Jimeno (2001): "Female employment and occupational changes in the 1990s: How is the EU performing relative to the US?," European Economic Review, 45, 875-889.

[19] EU (2002): "Presidency Conclusions," Barcelona European Council 15 and 16 March 2002, Barcelona.

[20] Gaviria, A. (2002): "Intergenerational mobility, sibling inequality and borrowing constraints," Economics of Education Review, 21(4), 331-340.

[21] Gelbach, J. B. (2002): "Public Schooling for Young Children and Maternal Labor Supply," American Economic Review, $92(1), 307-322$.

[22] Gulbrandsen, L., J. A. Lea, And S. Stokke (1982): "Barnetilsyn hos småbarnsfamilier: presentasjon av data fra en survey-undersøkelse blant småbarnsforeldre i Oslo høsten 1981," INAS notat 82:13, Institutt for anvendt sosialvitenskapelig forskning, Oslo.

[23] Havnes, T., AND M. Mogstad (2009): "No Child Left Behind. Universal Child Care and Children's Long-Run Outcomes," Discussion Papers 582, Statistics Norway.

[24] Heckman, J., H. Ichimura, J. Smith, And P. Todd (1998): "Characterizing Selection Bias Using Experimental Data," Econometrica, 66(5), 1017-1098.

[25] Heckman, J. J. (1974): "Effects of Child-Care Programs on Women's Work Effort," Journal of Political Economy, 82(2), S136-S163.

[26] Hægeland, T., O. RaAum, And K. G. Salvanes (2008): "Pennies from Heaven? Using Exogeneous Tax Variation to Identify Effects of School Resources on Pupil Achievements," IZA Discussion Papers 3561, Institute for the Study of Labor (IZA).

[27] Imbens, G. W., AND J. M. Wooldridge (2009): "Recent Developments in the Econometrics of Program Evaluation," Journal of Economic Literature, 47(1), 5-86.

[28] Jaumotte, F. (2003): "Female Labour Force Participation: Past Trends and Main Determinants in OECD Countries," OECD Economics Department Working Papers 376, OECD Economics Department.

[29] Karoly, L. A., M. R. Kilburn, And J. S. Cannon (2005): Early Childhood Interventions: Proven Results, Future Promise. RAND Corporation, Santa Monica, CA.

[30] Kimmel, J. (1998): "Child Care Costs as a Barrier to Employment for Single and Married Mothers," The Review of Economics and Statistics, 80(2), 287-299.

[31] Knudsen, E. I., J. J. Heckman, J. L. Cameron, And J. P. Shonkoff (2006): "Economic, neurobiological, and behavioral perspectives on building America's future workforce," Proceedings of the National Academy of Sciences, 103(27), 1015510162.

[32] Kornstad, T., And T. O. Thoresen (2007): "A discrete choice model for labor supply and childcare," Journal of 
Population Economics, 20(4), 781-803.

[33] Lefebvre, P., AND P. Merrigan (2008): "Child-Care Policy and the Labor Supply of Mothers with Young Children: A Natural Experiment from Canada," Journal of Labor Economics, 26(3), 519-548.

[34] LeirA, A. (1992): Welfare States and Working Mothers. Cambridge University Press.

[35] Lundin, D., E. Mörk, AND B. ÖCKERT (2008): "How far can reduced childcare prices push female labour supply?," Labour Economics, 15(4), 647-659.

[36] Michalopoulos, C., P. K. Robins, And I. Garfinkel (1992): "A Structural Model of Labor Supply and Child Care Demand," Journal of Human Resources, 27(1), 166-203.

[37] NOU (1972:39): "Preschools," White paper, Ministry of children's and family affairs.

[38] Rhode, P. W., AND K. S. Strumpf (2003): "Assessing the Importance of Tiebout Sorting: Local Heterogeneity from 1850 to 1990," American Economic Review, 93(5), 1648-1677.

[39] Rosen, S. (1996): "Public Employment and the Welfare State in Sweden," Journal of Economic Literature, XXXIV, $729-740$.

[40] Schlosser, A. (2005): "Public Preschool and the Labor Supply of Arab Mothers: Evidence from a Natural Experiment," Discussion paper, Dept. of Economics, The Hebrew University of Jerusalem. 


\section{Appendix A}

Table A1: Descriptive statistics of mothers with the youngest child 7 to 10 years of age

\begin{tabular}{lcccccc}
\hline & \multicolumn{2}{c}{ Treated, $\mathbf{1 9 7 6}$} & \multicolumn{2}{c}{$\begin{array}{c}\text { Diff. in means } \\
\text { Treat. }- \text { Comp. }\end{array}$} & \multicolumn{2}{c}{$\begin{array}{c}\text { Normalized diff. } \\
\text { Treat. Comp. }\end{array}$} \\
& Mean & $\mathrm{SD}$ & 1976 & 1979 & 1976 & 1979 \\
\hline Dependent variables & & & & & \\
Maternal employment & 0.315 & 0.4645 & 0.0318 & 0.0287 & 0.0347 & 0.0296 \\
Full time equivalent & 0.1011 & 0.3015 & 0.0163 & 0.019 & 0.028 & 0.0305 \\
\hline Control variables & & & & & \\
Employment rate & 0.8679 & 0.0401 & -0.001 & -0.0003 & -0.0126 & -0.0042 \\
Age & 38.48 & 6.20 & 0.2494 & 0.204 & 0.0199 & 0.0175 \\
Husband's age & 41.82 & 7.35 & 0.1419 & 0.0608 & 0.0096 & 0.0043 \\
Education (years) & 9.48 & 2.11 & 0.3001 & 0.2952 & 0.0736 & 0.0719 \\
Husband's edu. (years) & 10.39 & 2.92 & 0.4211 & 0.3815 & 0.0748 & 0.0685 \\
Children 3-6 y.o. & 0 & 0 & 0 & 0 & 0 & 0 \\
Children 7-10 y.o. & 1.2276 & 0.4193 & -0.0058 & 0.0027 & -0.0069 & 0.0032 \\
Children 11-15 y.o. & 0.7775 & 0.7147 & -0.0207 & -0.0228 & -0.0144 & -0.0162 \\
Immigrant & 0.0369 & 0.1885 & 0.0086 & 0.0097 & 0.0243 & 0.0264 \\
Relocated & 0.0205 & 0.1417 & 0.0000 & 0.0028 & 0.0000 & 0.0099 \\
\hline Sample size & \multicolumn{7}{c}{ Treated } & 1979 & 1976 & 1979 \\
\hline
\end{tabular}

Notes: Treatment (comparison) municipalities are above (below) the median in child care coverage growth from 1976 to 1979. Outcome and control variables are defined in Section 5. Standard deviations are denoted SD, and normalized differences are defined as differences in averages by treatment status, scaled by the square root of the sum of variances. 

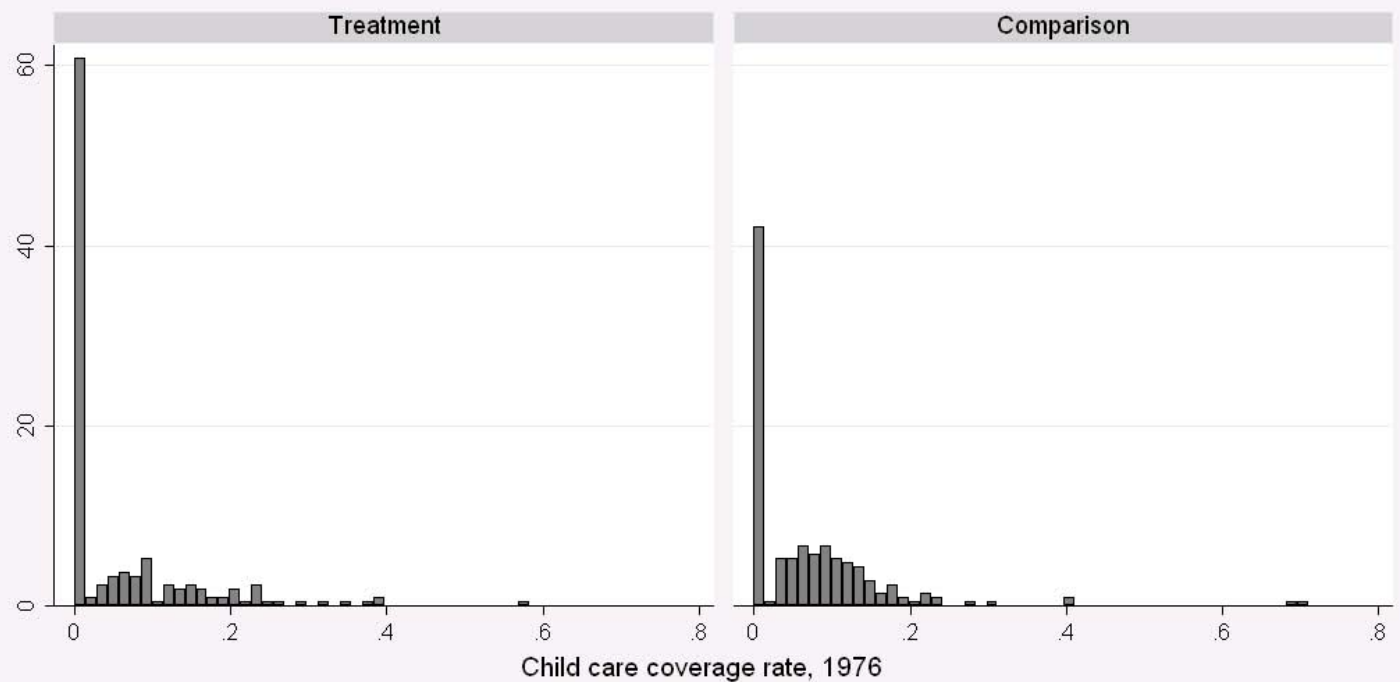

Graphs by treatment

(a) 1976

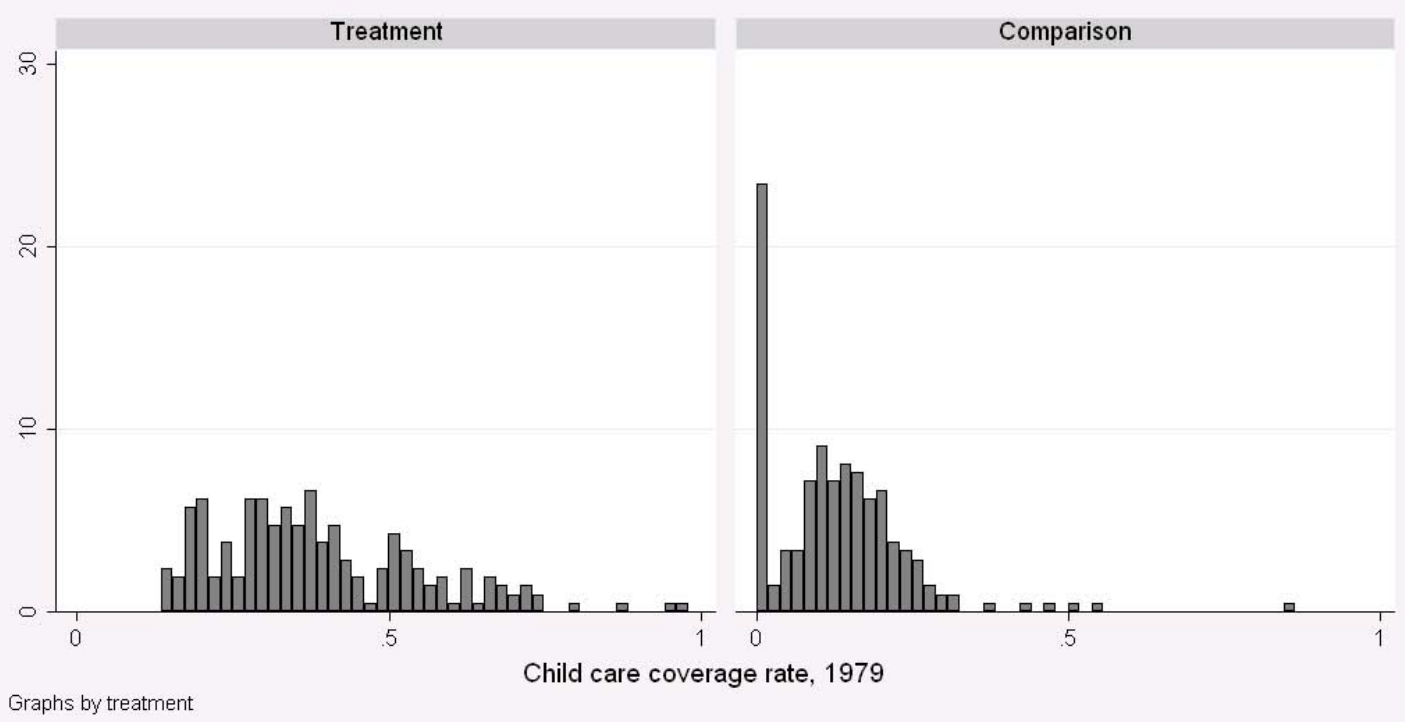

(b) 1979

Figure A1: Distribution of treatment and comparison municipalities by child care coverage for 3 to 6 year olds in 1976 (top panel) and 1979 (bottom panel)

Notes: Treatment (comparison) municipalities are above (below) the median in child care coverage growth from 1976 to 1979. 
Table A2: DD-estimations with control variables as dependent variables

\begin{tabular}{lccccc}
\hline & $(1)$ & $(2)$ & $(3)$ & $(4)$ & $(5)$ \\
& Estimate & $\mathrm{SE}$ & Mean & Estimate/ $\Delta C C$ & $\mathrm{~N}$ \\
\hline Employment rate & $0.0008^{* * *}$ & 0.0001 & 0.8682 & $0.0045^{* * *}$ & 252,699 \\
Age & -0.0043 & 0.0239 & 32.3014 & -0.0239 & 252,699 \\
Husband's age & 0.0314 & 0.0305 & 35.1704 & 0.1759 & 252,625 \\
Education (years) & -0.0114 & 0.0135 & 9.8928 & -0.0637 & 250,163 \\
Husband's edu. (years) & -0.0019 & 0.0178 & 10.5964 & -0.0108 & 250,088 \\
Children 7-10 y.o. & $-0.0110^{* * *}$ & 0.0045 & 0.5919 & $-0.0617^{* * *}$ & 252,699 \\
Children 11-15 y.o. & $-0.0079^{* *}$ & 0.0041 & 0.3481 & $-0.0443^{* *}$ & 252,699 \\
Immigrant & 0.0017 & 0.0015 & 0.0387 & 0.0097 & 252,699 \\
Relocated & $0.0041^{* * *}$ & 0.0016 & 0.0455 & $0.0231^{* * *}$ & 252,699 \\
\hline
\end{tabular}

${ }^{*} p<0.10,{ }^{* *} p<0.05,{ }^{* * *} p<0.01$ (one-tailed)

Notes: Estimations are based on OLS on equation (1), with controls listed in Table 2 and municipality-specific fixed effects, excluding the dependent variable from the set of controls. The full sample consists of 252,699 married mothers with the youngest child aged 3-6 years. Missing observations of the dependent variable are excluded from each estimation. $\Delta C C$ is defined as the increase in child care coverage following the reform in the treatment group relative to the comparison group. Mean refers to the pre-reform means in the treatment group. Standard errors (SE) are clustered on the mother and robust to heteroskedasticity. 
Table A3: Descriptive statistics for treatment and comparison municipalities in 1976

\begin{tabular}{|c|c|c|c|c|}
\hline \multirow[b]{2}{*}{ Child care coverage rate } & \multicolumn{2}{|c|}{ Treatment } & \multicolumn{2}{|c|}{ Comparison } \\
\hline & 0.0534 & {$[0.0899]$} & 0.0695 & [0.0968] \\
\hline Years of education, males & 9.2256 & {$[0.5514]$} & 9.2174 & {$[0.4699]$} \\
\hline- , females & 8.8198 & {$[0.3820]$} & 8.7672 & {$[0.3313]$} \\
\hline Earnings, males & 0.3917 & {$[0.0762]$} & 0.4081 & {$[0.0734]$} \\
\hline- , females & 0.1080 & {$[0.0349]$} & 0.1121 & {$[0.0321]$} \\
\hline Employment, males & 0.8324 & {$[0.0591]$} & 0.8367 & {$[0.0665]$} \\
\hline- , females & 0.2919 & {$[0.0844]$} & 0.2997 & {$[0.0813]$} \\
\hline \multicolumn{5}{|c|}{ Expenditure and revenue (1000 NOK/capita) } \\
\hline Total expenditure & 6.2377 & {$[1.8918]$} & 5.9132 & [1.4921] \\
\hline Ear marks, total & 3.702 & {$[1.4167]$} & 3.5522 & {$[1.1317]$} \\
\hline Fees, total & 0.8102 & {$[0.5852]$} & 0.6826 & {$[0.4147]$} \\
\hline Taxes & 2.4635 & {$[0.6825]$} & 2.4641 & {$[0.7459]$} \\
\hline \multicolumn{5}{|l|}{ Geography } \\
\hline In densely populated areas & 0.4049 & {$[0.2915]$} & 0.4827 & [0.2979] \\
\hline Ave. distance to zone center & 0.8876 & {$[0.7789]$} & 0.7732 & [0.6788] \\
\hline - to neighboring center & 3.7768 & {$[2.6130]$} & 3.4297 & {$[2.8039]$} \\
\hline \multicolumn{5}{|l|}{ Population } \\
\hline Total & 9,846 & {$[36,400]$} & 9,476 & {$[13,267]$} \\
\hline Married & 0.4664 & {$[0.0277]$} & 0.4618 & {$[0.0346]$} \\
\hline Divorced & 0.0144 & {$[0.0081]$} & 0.0153 & {$[0.0080]$} \\
\hline Immigrant & 0.0098 & {$[0.0096]$} & 0.0095 & {$[0.0086]$} \\
\hline 0 to 6 years old & 0.1077 & {$[0.0177]$} & 0.1141 & {$[0.0177]$} \\
\hline 7 to 10 years old & 0.0673 & {$[0.0099]$} & 0.0708 & {$[0.0097]$} \\
\hline 11 to 18 years old & 0.1293 & {$[0.0127]$} & 0.1314 & {$[0.0133]$} \\
\hline Females: 19 to 35 years old & 0.1021 & {$[0.0187]$} & 0.1082 & {$[0.0170]$} \\
\hline$-: 36$ to 55 years old & 0.1027 & {$[0.0101]$} & 0.1019 & {$[0.0095]$} \\
\hline Males: 19 to 35 years old & 0.1175 & {$[0.0152]$} & 0.1227 & {$[0.0137]$} \\
\hline -: 36 to 55 years old & 0.1096 & {$[0.0091]$} & 0.1077 & {$[0.0092]$} \\
\hline \multicolumn{5}{|l|}{ Politics } \\
\hline Registered voters & 6,480 & {$[26,654]$} & 5,863 & {$[8,488]$} \\
\hline- , female & 0.4896 & {$[0.0169]$} & 0.4928 & {$[0.0167]$} \\
\hline Election participation & 0.7243 & {$[0.0587]$} & 0.7093 & {$[0.0563]$} \\
\hline- , females & 0.7094 & {$[0.0666]$} & 0.6962 & {$[0.0632]$} \\
\hline Female elected representatives & 0.1521 & {$[0.0807]$} & 0.1394 & {$[0.0635]$} \\
\hline Socialist vote share & 0.3864 & {$[0.1654]$} & 0.4031 & {$[0.1651]$} \\
\hline
\end{tabular}

Notes: Columns 1-4 report means and standard deviations (in brackets) across treatment and comparison municipalities, not weighted by population size. Earnings are measured in NOK 100,000. Employment is defined in Section 5. Socialist parties are defined as RV, SV and DNA. Densely populated areas are contiguous zones of at least 200 people where the distance between houses is generally less than 50 meters ( 400 meters if separated by e.g. parks, rivers or industrial zones). Average distance to zone center is the mean predicted travel distance in $\mathrm{km}$ from a citizen's home to the most populous census area in a contiguous zone of more than 2,000 people within the municipality. Distance to neighboring center is the mean travel distance from the center of a census area to the closest center in another census area within the same economic zone. 
Table A4: Estimates of the effect of child care on various income thresholds

\begin{tabular}{lccccc}
\hline & $(1)$ & $(2)$ & $(3)$ & $(4)$ & $(5)$ \\
& Estimate & $\mathrm{SE}$ & Mean & Estimate/ $\Delta C C$ & $\mathrm{~N}$ \\
\hline Earnings $>$ 1BA & $0.0063^{* *}$ & 0.0035 & 0.3619 & $0.0351^{* *}$ & 252,699 \\
Earnings $>$ 2BA & $0.0111^{* * *}$ & 0.0031 & 0.2452 & $0.0624^{* * *}$ & 252,699 \\
Earnings $>$ 3BA & $0.0148^{* * *}$ & 0.0025 & 0.153 & $0.0829^{* * *}$ & 252,699 \\
Earnings $>$ 4BA & $0.0092^{* * *}$ & 0.002 & 0.0888 & $0.0518^{* * *}$ & 252,699 \\
Earnings $>$ 6BA & $0.0019^{* * *}$ & 0.0008 & 0.016 & $0.0109^{* * *}$ & 252,699 \\
Earnings $>$ 8BA & 0.0003 & 0.0004 & 0.0032 & 0.0019 & 252,699 \\
\hline
\end{tabular}

${ }^{*} p<0.10,{ }^{* *} p<0.05,{ }^{* * *} p<0.01$ (one-tailed)

Notes: Estimations are based on OLS on equation (1), with controls listed in Table 2 and municipality-specific fixed effects. The full sample consists of 252,699 married mothers with the youngest child aged 3-6 years. $\Delta$ is defined as the increase in child care coverage following the reform in the treatment group relative to the comparison group. Mean refers to the prereform means in the treatment group. Standard errors (SE) are clustered on the mother and robust to heteroskedasticity. BA refers to basic amounts, defined in Section 5. In 2006, one basic amount is about USD 10,500 in annual earnings. 


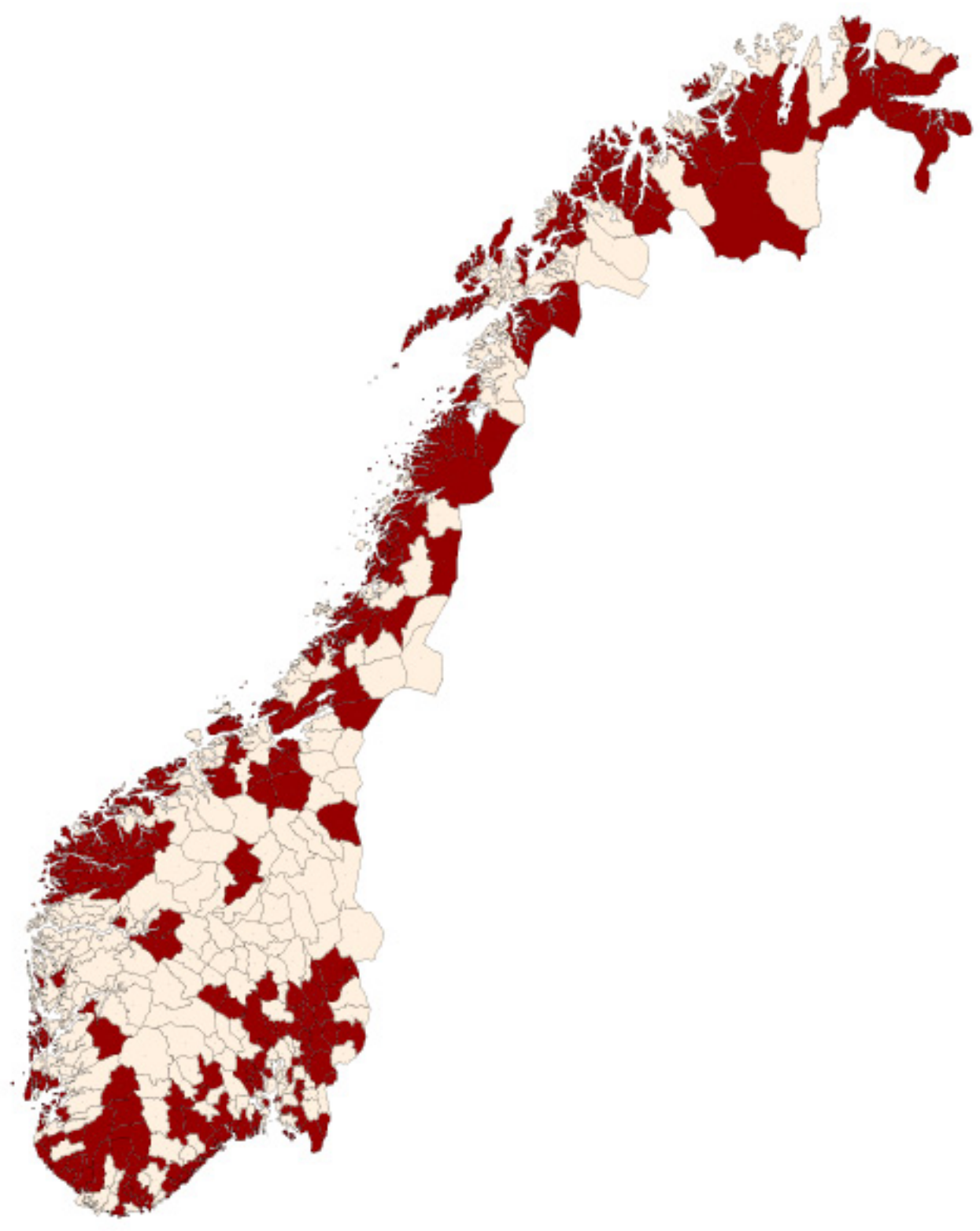

Figure A2: Geographical location of treatment (white) and comparison (dark) municipalities 